\title{
Maternal self-efficacy beliefs as predictors of parenting competence and toddlers' emotional, social, and cognitive development
}

\author{
Priscilla Kari Coleman \\ West Virginia University
}

Follow this and additional works at: https://researchrepository.wvu.edu/etd

\section{Recommended Citation}

Coleman, Priscilla Kari, "Maternal self-efficacy beliefs as predictors of parenting competence and toddlers' emotional, social, and cognitive development" (1998). Graduate Theses, Dissertations, and Problem Reports. 3118.

https://researchrepository.wvu.edu/etd/3118

This Dissertation is protected by copyright and/or related rights. It has been brought to you by the The Research Repository @ WVU with permission from the rights-holder(s). You are free to use this Dissertation in any way that is permitted by the copyright and related rights legislation that applies to your use. For other uses you must obtain permission from the rights-holder(s) directly, unless additional rights are indicated by a Creative Commons license in the record and/ or on the work itself. This Dissertation has been accepted for inclusion in WVU Graduate Theses, Dissertations, and Problem Reports collection by an authorized administrator of The Research Repository @ WVU.

For more information, please contact researchrepository@mail.wvu.edu. 
MATERNAL SELF-EFFICACY BELIEFS AS PREDICTORS OF PARENTING COMPETENCE AND TODDLERS' EMOTIONAL, SOCIAL, AND COGNITIVE DEVELOPMENT

By

Priscilla K. Coleman

\title{
A DISSERTATION
}

\author{
Submitted to \\ The Eberly College of Arts and Sciences \\ at \\ West Virginia University \\ in partial fulfillment of the requirements \\ for the degree of \\ Doctor of Philosophy \\ in \\ Life-Span Developmental Psychology
}

Department of Psychology

Morgantown, West Virginia 1998

Committee Chair: Katherine H. Karraker, Ph.D. 


\begin{abstract}
MATERNAL SELF-EFFICACY BELIEFS AS PREDICTORS OF PARENTING COMPETENCE AND TODDLERS' EMOTIONAL, SOCIAL, AND COGNITIVE DEVELOPMENT
\end{abstract}

\title{
By Priscilla K. Coleman
}

Appreciation for cognitive factors associated with parental competence and child outcomes has expanded dramatically in developmental research over the past several years. Parental selfefficacy beliefs, in particular, have emerged as both a salient direct predictor of positive parenting practices and as a mediator of the effects of several of the most thoroughly researched correlates of parenting quality including maternal depression, child temperament, and social support. Parental self-efficacy beliefs embody an estimation of the degree to which parents perceive themselves as capable of performing the varied tasks associated with this demanding role.

The objectives of this study were threefold and entailed the following: a) examination of parenting self-efficacy beliefs as predictors of overt measures of competence in the parenting of toddlers, b) extension of the parenting self-efficacy research beyond indexes of parental competence to assess self-efficacy beliefs as possible predictors of specific indexes of toddlers' behavior and development, and c) investigation of the degree to which maternal self-efficacy beliefs mediate the effects of toddler temperament and maternal variables on measures of parenting competence, parenting satisfaction, and parenting stress.

Forty-two predominantly middle-class mother-toddler pairs residing in a rural southeastern city participated in this study. Mothers completed a number of questionnaires, toddlers were administered the Bayley Scales of Infant Development, and each dyad participated in the Crowell Procedure, which is a laboratory technique developed to observe parent and toddler behaviors in a semi-structured context.

Counter to expectations, both domain-specific and domain-general self-efficacy beliefs failed to significantly predict parenting competence and various child behaviors observed during 
the Crowell Procedure. However, using Baron and Kenny’s (1986) recommended mediation techniques, evidence for domain-specific self-efficacy beliefs operating as a mediator between toddler temperament and both parenting stress and parenting satisfaction was revealed.

Implications of the findings are discussed and suggestions for future research are provided. 
MATERNAL SELF-EFFICACY BELIEFS AS PREDICTORS OF PARENTING COMPETENCE AND TODDLERS' EMOTIONAL, SOCIAL, AND COGNITIVE DEVELOPMENT

By

Priscilla K. Coleman

\section{A DISSERTATION}

Submitted to

West Virginia University

in partial fulfillment of the requirements

for the degree of

Doctor of Philosophy

in

Life-Span Developmental Psychology

\section{APPROVAL OF EXAMINING COMMITTEE}

Stanley Cohen, Ph.D.

Wanda Franz, Ph.D.

Cheryl McNeil, Ph.D.

Anne C. Watson, Ph.D.

Katherine H. Karraker, Ph.D., Chair

Date 
Copyright by

Priscilla Kari Coleman

1998 


\section{Dedication}

My dissertation is dedicated to the many people in my life who have provided the support and encouragement needed to make earning a doctorate feasible in the midst of raising a family. Without my father's tireless support, both emotional and financial, this goal would not have been attainable. Without Eileen's keen ability to identify my latent skills coupled with her active interest in convincing me that they were there, I would not have had the confidence to pursue the degree. Her kind and energetic presence in my life has been a boundless source of inspiration and support. Without Leonard's love and willingness to sacrifice the quality of our home life and his ability to take over when I was so preoccupied, doctoral training would not have been possible either. Our children have also sacrificed to make completion of this program a reality, and this project is dedicated to them as well. My hope is that the resultant gains will, over time, outweigh the period when their mom was pretty tapped out mentally, physically, and emotionally. Finally, I would like to dedicate this dissertation to Pastor Forsythe, whose love, prayers, and guidance before, during, and after our two year stay in West Virginia have been a source of great peace and comfort. 


\section{Acknowledgments}

First and foremost, I would like to thank Katherine Karraker for providing me with just the right balance between supervision and autonomy throughout my doctoral training. She cleverly kept a watchful eye over all that I was doing while also affording me the latitude to learn independently and pursue my own research interests. The occasional ropes she threw out to reel me back, reminding me that I wasn't quite ready to venture out unassisted, were much appreciated. Just as I would begin to feel uneasy or confused, she was there to provide precisely the right direction or perspective needed. Her personal sensitivity, knowledge of the field, professionalism, and her talent for mentoring her students in very individualized ways, have truly had an immense impact on my training and career aspirations. For all of this, I feel very much indebted

I would also like to thank Wanda Franz for taking the time from her busy life to serve on my committee. I feel very fortunate to have met Wanda, and to have had the opportunity to work with her and get to know her personally a little over the past couple of years. I appreciated her insight on parenting and development, and it was comforting to have someone with a similar life perspective on my committee.

I am grateful for the depth of knowledge, behavioral focus, and practical perspectives that both Anne O'Reilly and Cheryl McNeil contributed to my dissertation. Both of these faculty members have been very encouraging on both the professional and personal levels as well. Stan Cohen's sharp ability to focus in on the sketchy areas in need of conceptual clarity, and his talent for asking the right questions were most helpful. He was a much appreciated member of my committee. 
Table of Contents

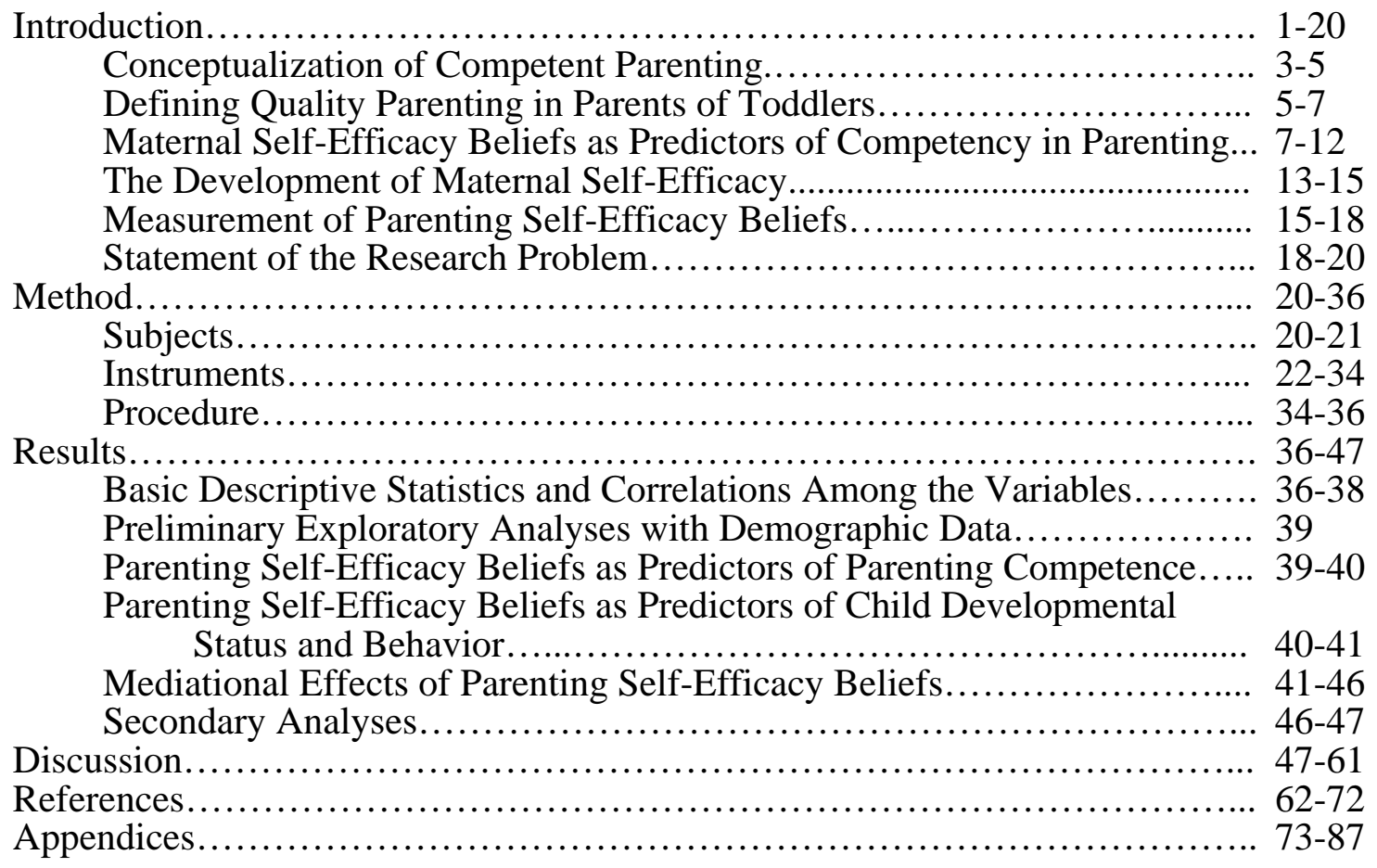


List of Tables

Table 1 Overview of Maternal Behaviors Coded During the Crowell Procedure............ 28

Table 2 Focusing the Child on the Task Coding Rubric.................................. 29

Table 3 Secure Base Coding Scheme.......................................... 30

Table 4 Crowell Procedure Toddler Variables..................................... 32

Table 5 Descriptive Statistics for Study Variables.................................. 37

Table 6 Zero-Order Correlations Among Study Variables............................ 38

Table 7 Regression Equations to Test for the Mediational Role of Domain-Specific Self-Efficacy Beliefs in Parenting Behavior .................................... 43

Table 8 Regression Equations to Test for the Mediational Role of Domain-General Self-Efficacy Beliefs in Parenting Behavior .............................. 45

Table 9 Results of Univariate F Tests from a MANOVA with Form of Child Care as the Independent Variable and Crowell Procedure Toddler Behaviors as the Dependent Variables.......................................................... 46

Table 10 Zero-Order Correlation Coefficients for SEPTI-TS Subscales and Crowell Procedure Variables 


\section{List of Appendices}

Appendix A Demographic Questionnaire................................. 73-74

Appendix B The Self-Efficacy for Parenting Tasks Index - Toddler Scale........ 75-77

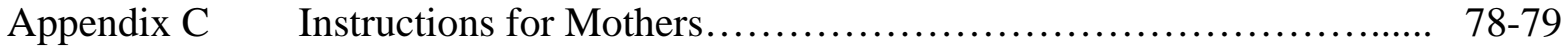

Appendix D Rating of Supportive Presence................................. 80-81

Rating of Quality of Assistance.............................. 82-83

Appendix E $\quad$ Mother Behavior Coding Sheets................................. 84-85

Appendix F Sample Coding Scheme for Toddler Behavior...................... 86

Appendix G $\quad$ Toddler Variables Coding Sheet.............................. 87 
Maternal Self-Efficacy Beliefs as Predictors of Parenting Competence and Toddlers' Emotional, Social, and Cognitive Development

Conceptualizing or defining positive, effective parenting in a general way is a relatively easy task. Most individuals living in western cultures, where children are revered, would agree that "good" parenting practices encompass those that most efficiently foster optimal physical, emotional, social, and cognitive development in children. Ideally such techniques likewise feel appropriate, comfortable, and satisfying to the parents, while also encouraging parents' personal growth. However, identification of the precise parental cognitive, affective, and behavioral components and processes associated with parental competency represents an exceedingly more complex and demanding endeavor. Moreover, an essential task for developmentalists is to specify the interactive processes through which the various cognitive, affective, and behavioral components of parenting combine with each other and with additional factors (e.g., parental individual difference factors, child characteristics, and the sociodemographic context) to produce high quality parenting and desirable child outcomes.

Within a general conceptualization of the diverse factors likely to converge to produce competent parenting, parental cognitions have historically received the least amount of research attention. However, many contemporary researchers have recognized that certain parental cognitions exhibit considerable power in terms of predicting various behavioral indicators of parenting competence. In particular, recent studies have highlighted parental self-efficacy beliefs as a seemingly central correlate of parenting quality (e. g., Bugental, Blue, \& Cruzcosa, 1989; Cutrona \& Troutman, 1986; Teti \& Gelfand, 1991). Parental self-efficacy beliefs are broadly defined as parents' self-referent estimations of competence in the parental role. Implicit in such cognitions is knowledge of appropriate parenting behaviors and confidence in one's own abilities to perform them (Bandura, 1989).

Building on this recent wave of parental self-efficacy research, the general aims of this dissertation include the following: 1) exploration of maternal self-efficacy beliefs, assessed at two different levels of analysis, as predictors of parenting quality, 2) examination of maternal 
self-efficacy beliefs as predictors of toddler behavior and developmental status, and finally 3) investigation of the mediational role of maternal self-efficacy beliefs in relationships between toddler temperament, maternal child care experience, and maternal attachment to their mothers and parenting competence, parenting satisfaction, and stress associated with parenting.

This study and most of the existing research related to parenting self-efficacy is correlational in nature, precluding the determination of the direction of effects. However, the design of this study is based on a conceptual framework that makes the assumption that selfefficacy beliefs do act as a causal agent in the determination of parenting behavior and child outcomes. Future, higher constraint research may certainly reveal that this assumption is erroneous, with bi-directional or multidirectional, or even non-linear effects operating instead among self-efficacy beliefs, parenting quality, and child behavior. This assumption of causality has also motivated most of the existing literature. Causal inferences made throughout this dissertation, although consistent with previous work in the area, have generally not been empirically supported.

The objectives of this dissertation were pursued with mother-toddler dyads as the participants. The toddler period was selected as the focus of the present study for a number of reasons. First, because the tasks associated with effective parenting during toddlerhood change dramatically from the infancy period based on toddlers' expanding abilities, parents are forced to develop new skills. According to self-efficacy theory and related research, the acquisition of new skills is greatly enhanced by perceptions of competence (Bandura, 1982).

Second, in view of the fact that the salience of self-efficacy beliefs as a predictor of overt parental responses tends to be enhanced under stressful circumstances (Bandura, 1982), the decision was made to observe parent and child behavior during a relatively difficult phase of early child development. By 19-23 months of age, most toddlers are highly mobile, are actively involved in exploring the environment, are rapidly becoming familiar with the limits imposed on them, and are striving for a new level of autonomy from the primary caregiver. Nevertheless, 
testing 19- to 23-month-old toddlers also avoids the periods of marked behavioral disregulation, regression in the child, and stress in the parent-child system which typify the primary developmental transitional periods occurring at 12, 15, 18, 24, and 36 months of age (Brazelton, 1992).

Third, 19-23 months was selected as an appropriate age for testing toddlers in view of McCall's (1981) model, which suggests that during the first 18 months of life development tends to progress along a relatively narrow, species-typical trajectory in the presence of normal rearing environments. According to the model, it is not until after 18 months that environmental and organismic differences tend to exert a significant impact on development. Finally, as recently pointed out by Resnick, Corley, and Robinson (1997), the age period between one and two years represents the phase of the lifespan that psychologists know the least about.

The introduction portion of this dissertation is divided into six segments. The first part outlines general perspectives on parental competency, with the second section devoted to providing an overview of research on specific parental behaviors that have been associated with child development during toddlerhood. In the next section, theoretical and empirical work relevant to maternal self-efficacy beliefs as predictors of competency in parenting is examined. The fourth segment is devoted to exploration of possible antecedents to the development of maternal self-efficacy beliefs. In the fifth section, research and theory pertaining to different approaches to the measurement of self-efficacy beliefs is described. Finally, in the last segment, specific objectives of this project are described in detail and the hypotheses to be tested are provided.

\section{Conceptualization of Competent Parenting}

For several years, developmental researchers have invested a considerable amount of interest and energy in examining and describing behavioral styles of parenting associated with various positive and negative child outcomes (Macoby \& Martin, 1983). This approach to the study of child development is considered unidirectional, because child outcomes are viewed as the product of the exclusive influence of parental behavior on children. Stafford and Bayer 
(1993) reviewed numerous unidirectional studies and found the following parental behaviors to be associated with positive socio-emotional outcomes in children: warmth (also studied as nurturance, responsiveness, support, or acceptance), contingent reinforcement, suggestive (as opposed to directive) statements during interaction, curiosity-promoting behaviors, encouragement of independence, involving children in decision making, flexible parenting, avoiding high power-assertive techniques, and relatively high demandingness.

In contrast to the unidirectional approach, which essentially framed child development research for decades, other researchers (Belsky, 1981, 1984; Hinde \& Stevenson-Hinde, 1987; Vondra \& Belsky, 1993) have preferred to adopt a systems approach to understanding parental behavior. The systems perspective recognizes that "...all individuals and relationships within the family interactively and reflexively shape all other family members and relationships" (Stafford \& Bayer, 1993, p. 123). Belsky (1984), a vocal adherent of the systems perspective, proposed that there are three principle sources or levels of parental influence on the global construct of parenting behavior: (1) the personal and psychological resources of the parent, (2) characteristics of the child, and (3) the broader context in which the parent-child relationship develops.

Personal and psychological resources of the parents that have been extensively studied in conjunction with parental competency include the following: personality variables (Luster \& Mittelstaedt, 1993), maternal stress (Hagekull \& Bohlin, 1990; Nakagawa, Teti \& Lamb, 1992), maternal depression (Cox, Puckering, Pound \& Mills, 1987; Field, 1984; Field et al., 1988; Gelfand \& Teti, 1990; Radke-Yarrow, 1990; Teti, Gelfand, Messinger, \& Isabella, 1995), maternal child care experience and knowledge of child development (Conrad, Gross, Fogg, \& Ruchala, 1992; Stoiber \& Houghton, 1993), maternal attitudes (Bohlin \& Hagekull, 1987), maternal beliefs about parenting (Kochanska, 1990; Pridham \& Chang, 1985), maternal desires (Bohlin \& Hagekull, 1987), maternal expectations (Glass, 1983; Hagekull \& Bohlin, 1990, Stoiber \& Houghton, 1993), and maternal self-efficacy beliefs (Bohlin \& Hagekull, 1987; Conrad, et al., 1992, Cutrona \& Troutman, 1986; Donovan, Leavitt \& Walsh, 1990; Johnston \& Mash, 1989; Teti \& Gelfand, 1991). 
Examples of characteristics of the child that have been systematically examined with respect to parental competency are temperament (Cohen \& Bromet, 1992, Crockenberg, 1986; Hagekull \& Bohlin, 1990), activity level (Buss, 1981), and social competency (Macoby, 1984; Patterson, 1976). Finally, some of the contextual factors that have been studied relative to parental competency include socio-economic status (Blumberg, 1980; Cohen \& Bromet, 1992) and social/marital support (Andressen \& Telleen, 1992; Bohlin \& Hagekull, 1987; Cohen \& Bromet, 1992, Cronenwett, 1985; Melson, Ladd, \& Hsu, 1993).

Under the general domain of parental personal and psychological resources, the study of parental cognitions represents a relatively broad area, encompassing parents' self-efficacy beliefs, values, expectations, knowledge, and desires. For a period spanning nearly 50 years, developmentalists studying parent-child interactions concentrated their attention on overt parenting practices and behavior (Smetana, 1994). As a result, cognitive, or more subjective, mentalistic elements of the parenting experience remained essentially outside the realm of mainline research efforts until quite recently (Smetana, 1994). The inclusion of cognitive factors illustrates an appreciation for the totality of the experience of parenting that was lacking in earlier research (Smetana, 1994). The initial motivation underlying the inclusion of cognitive elements in research strategies was an attempt to enhance the prediction of child outcomes beyond what was possible with the earlier, more circumscribed research focus on parental behavioral responses (Grusec, Hastings, \& Mammone, 1994). However, within the last 5 or 10 years, the study of parental cognitions has been acknowledged as a research domain worthy of examination for its own sake (Smetana, 1994). Continuing with the latest line of research, directed toward understanding the role of parental cognitions in parenting behavior, the primary purpose of the present study was to examine the extent to which self-efficacy beliefs predict parental competency and toddler outcomes.

\section{Defining Quality Parenting in Parents of Toddlers}

The difficulty inherent in defining the parameters of positive parenting is particularly apparent in attempts to specify critical behaviors in parents of toddlers, given the rapid changes 
that occur across all domains of development during this age period. Toddlerhood represents a period of development dominated by the child's emerging needs for independence and exploration of the environment, with rapid developmental changes presenting entirely new challenges to parents that were not present during infancy. Several additional changes transpiring during toddlerhood have been summarized by Edwards (1995). Specifically, in conjunction with toddlers' efforts to learn to function more autonomously, they develop skills for more effective interdependent functioning, become aware of themselves as separate beings, and develop the capacity to engage in self-reflection. During toddlerhood the beginnings of self-control, empathetic responding, awareness of moral standards, and gender identity formation are also evidenced. Attachment to primary caregivers is typically well-established by toddlerhood and a burgeoning interest in forming attachments to peers begins. Finally, substantial cognitive advances are achieved during toddlerhood, with the most notable perhaps being the ability to engage in symbolic mental representation and related gains in the language area. The focus of the current investigation was on parental correlates of toddler behavior and development; therefore, in the ensuing discussion, empirical evidence pertaining to parental variables found to have an association with the nature of child outcomes will be examined.

Maternal factors that have been found to be associated with socio-emotional development in toddlers include the following: sensitivity (van den Boom, 1994; van IJzendoorn et al., 1995), maternal positive affect (Lyons-Ruth, Connell, Zoll, \& Stah (1987), quality of bodily contact (Main \& Stadtman, 1981), use of appropriate pacing in interactions (Egeland \& Farber, 1984), nonrestrictive care (Lamb, Thompson, Gardner, \& Charnov, 1985), and maternal engagement or preoccupation (Bohlin \& Hagekull, 1987).

Attempts to describe parental determinants of toddler development in the cognitive realm have not been as abundant as research efforts geared toward describing parental correlates of socio-emotional functioning in children. Nevertheless, there has been some concentrated effort geared toward isolating the key parental behaviors and attributes associated primarily with early cognitive development of children. For example, Slade (1987) found that mothers' availability 
for interactive play and conversation was significantly related to toddlers' abilities to engage in symbolic or pretend play. Other research has revealed that toddlers' vocabulary development is related to the amount of parental speech (Huttenlocher, Haight, Bryk, Seltzer, \& Lyons, 1991) and parental efforts to describe environmental stimuli that capture a toddler's attention (Dunham \& Dunham, 1992). Bus and van IJzendoorn (1988) reported that parent-child interactive routines involving activities such as book reading were additional strong predictors of vocabulary development in toddlers. In a review of early parental characteristics that are predictive of later cognitive development, MacPhee, Ramey, and Yeates (1984) delineated the following constellation of parenting attitudes and behaviors: engagement in intellectually challenging activities, provision of a variety of stimulating experiences for the child, the level or amount of interaction, interactional reciprocity, how intrusive or ignoring the parent is, the emotional tone of social exchanges, the use of praise and encouragement, and contingent verbal responsiveness.

Interestingly, the empirical work cited herein reveals considerable overlap between parental attributes likely to foster socio-emotional growth and those that facilitate cognitive development in children. These key parental variables that encourage growth across diverse developmental domains may very well be related to a few central intervening variables, such as parental self-efficacy beliefs.

\section{Maternal Self-Efficacy Beliefs as Predictors of Competency in Parenting}

In order to establish the potential strength of the parental self-efficacy variable as a predictor of parental functioning, the general construct of self-efficacy, described by Bandura (1977; 1989), will first be reviewed. Second, the concept of self-efficacy as it relates to the maternal role will be defined. Third, specific studies that have examined parental self-efficacy in the context of parent-child relationships will be described.

The self-efficacy construct, postulated by Bandura (1977), refers to the belief in one's ability to successfully perform a particular behavior. Prerequisite to confidence in one's capacity to effectively engage in a given behavioral pursuit is the belief that appropriate actions exist that carry the potential to lead to the desired behavioral outcome (Wells-Parker, Miller, \& Topping, 
1990). Therefore, self-efficacy beliefs are interwoven with the knowledge of the particular behavior(s) that they relate to. According to social learning theory (Bandura, 1989), expectations related to personal efficacy originate from four primary informational sources. Personal accomplishment history (successes and failures) is perhaps the most obvious and direct influence on mastery expectations. However, vicarious experience also represents a potentially viable vehicle for the development of self-efficacy beliefs. Watching others engage in particular activities can generate estimations in observers pertaining to their own capacity for mastery in a given situation. According to Bandura, inferences from social comparison are by nature indirect; therefore, self-efficacy beliefs derived in this manner are characteristically more susceptible to change. Verbal persuasion represents the third mode through which self-efficacy beliefs may develop. This category of information represents verbal feedback from others regarding one's potential for accomplishment in a given area. Although appraisals by others can result in the formation of efficacy expectancies, they tend to be weaker than those derived directly from one's own achievements. The final means through which self-efficacy beliefs emerge is through emotional arousal. Individuals anticipate failure when they are inundated by aversive physiological arousal; and conversely, lower levels of arousal are likely to be associated with success expectancies.

The impact of environmental information on the development of personal efficacy is necessarily dependent on how such information is cognitively appraised or interpreted by the individual (Bandura, 1989). For example, success is more likely to enhance self-efficacy if performance is believed to result from skills, as opposed to factors that are external to the individual. Cognitive appraisals of the degree of challenge or difficulty level associated with a particular task can also affect the relative impact of performance accomplishments on perceived self-efficacy (Bandura, 1989). Obviously, success associated with tasks perceived to be fairly simple in nature provides little information regarding competency; whereas mastery of a very hard task conveys strong evidence of one's ability. As indicated by Bandura (1989), the rate and pattern of attainments also influence subjective estimations of efficacy. Apparently, the means 
through which self-efficacy beliefs develop and the intervening appraisal processes are complex and interrelated.

Having provided some general background information on the self-efficacy construct, it is now possible to focus attention on the more circumscribed domain of maternal self-efficacy beliefs. Maternal self-efficacy beliefs refer to the mother's expectations about the degree to which she is able to perform competently and effectively as a mother (Teti \& Gelfand, 1991). Maternal self-efficacy can also be construed as a mother's perceived ability to exercise positive influence on the behavior and development of her children. As noted earlier, according to the basic tenets of self-efficacy theory (Bandura, 1989), maternal self-efficacy beliefs should incorporate both the level of specific knowledge pertaining to the behaviors involved in child rearing and the degree of confidence a mother has in her ability to carry out the designated role behaviors. The work of Conrad et al. (1992) clearly illustrates the importance of each component of self-efficacy in association with mother-toddler interactions. Significant main effects of maternal knowledge of child development or maternal self-confidence were not detected using quality of mother-toddler interaction as the dependent measure; however, a significant interaction between the two independent variables was found. Among less confident mothers, the data revealed no differences in the quality of interaction based on maternal level of knowledge; but with the more confident mothers, an increase in knowledge resulted in more effective parentchild interaction. Apparently, confidence is necessary for mothers to be able to effectively put their knowledge to use, and confidence without knowledge does not have any positive association with the quality of interaction between mothers and toddlers.

Current research generally supports an association between high maternal self-efficacy and specific adaptive parenting skills, such as responsive, stimulating, and non-punitive caretaking (Unger \& Waudersman, 1985), and active maternal coping orientations (Wells-Parker, Miller, \& Topping, 1990), in addition to a relative absence of maternally perceived behavioral problems (Johnson \& Mash, 1989). Low maternal self-efficacy has been correlated with maternal depression (Cutrona \& Troutman, 1986; Teti \& Gelfand, 1991), actual behavior problems in 
children (Gibaud-Wallson \& Waudersman, cited in Johnston \& Mash, 1989), maternal perceptions of child difficulty (Gibaud-Wallson \& Waudersman, cited in Johnston \& Mash, 1989), and a passive coping style in the parental role (Wells-Parker, et al., 1990). Self-efficacy has also been found to be positively associated with some concrete behavioral tendencies, such as parental efforts to educate themselves about parenting by attending parent education programs and reading literature relevant to parenting (Spoth \& Conroy, 1993), and with parental efforts to teach their children injury protection (Peterson, Farmer, \& Kashani, 1990).

Parental self-efficacy beliefs have been found to be a particularly salient predictor of parental competency under depressed ecological conditions (Bandura, 1995; Halpern, 1993). More precisely, research by Elder (1995) has revealed that elevated levels of parenting selfefficacy serve as a critical buffer against pervasive environmental adversity, enabling parents to optimally promote their children's development.

Building on this expanding field of research linking maternal self-efficacy beliefs to maternal behavioral competence, a few studies have highlighted the importance of self-efficacy beliefs as a mediator of the effects of several historically recognized correlates of parenting quality including maternal depression, child temperament, and social support on parenting competence (Bugental et al., 1989; Goodnow \& Collins, 1990; Johnston \& Mash, 1989; Teti \& Gelfand, 1991). Psychologists have recognized the general significance of mediating variables for the better part of this century; as Baron and Kenny (1986) note, Woodworth's (1929) S-O-R model represents one of the earliest and most general formulations of the mediation hypothesis. Essentially an active organism's internal processes are postulated to intervene between environmental stimuli and the actual response of the organism. Mediators are incorporated into theoretical models to explain how environmental events take on psychological significance or account for relationships between predictors and criteria. Baron and Kenny's (1986) model and data analytic techniques have been widely applied in psychological research since the publication of their article devoted to clarifying the distinction between moderator and mediator variables 
over a decade ago. The causal chains involved in mediation as described by Baron and Kenny (1986) are depicted below.

\section{Mediator}

Independent Dependent

Variable Variable

In this simplified model, there are two causal paths between the independent and the dependent variables: a direct one and an indirect one which invokes an internal process variable such as self-efficacy. According to Baron and Kenny's model (1986), specific criteria for mediation include the following: a) the independent variable should be significantly associated with the dependent variable, $b$ ) the mediating variable should be significantly related to both the independent and the dependent variable, and c) when the mediating variable is controlled, the relationship between the independent and dependent variables should be reduced.

The mediational role of self-efficacy relative to parenting competence is exemplified by the work of Teti and Gelfand (1991). Building on Bandura's (1982; 1986) general framework, which proposes that self-efficacy represents the mediational link between knowledge and behavior, Teti and Gelfand specifically examined the degree to which maternal self-efficacy beliefs mediated the effects of various psychosocial variables on the behavioral competence of mothers of infants. When compared to more efficacious mothers, Teti and Gelfand expected mothers with compromised efficacy beliefs to be less decisive, less sensitive, and more awkward in their interactions with their children. This prediction was based on evidence that individuals with low self-efficacy lack the problem-solving skills and the persistence required for positive interactions. Using Baron and Kenny's (1986) mediational model, they found that maternal self-efficacy beliefs did in fact mediate the effects of social-marital supports and depression on mothers' behavioral competence. The relationships between each of these two predictors and maternal behaviors were reduced to non-significance with maternal self-efficacy in the equation. Perceptions of infant difficulty were also investigated as a predictor, but they were not found to be related to maternal competence after the effects of a number of demographic factors were controlled. However, difficulty perceptions did remain significantly related to self-efficacy 
beliefs after several demographic effects were removed. Moreover, maternal self-efficacy beliefs were significantly related to behavioral competence after controlling for maternal education, family income, infant age, and marital status in the first block of a hierarchical regression analysis and entering maternal depression, infant difficulty perceptions, and social-marital supports in the second block. In addition to performing the basic regression analyses required to establish mediation according to Baron and Kenny, Teti and Gelfand used a procedure outlined by Cohen and Cohen (1983) to examine the possibility that self-efficacy beliefs might interact with other independent variables in the prediction of maternal competence. A series of regression analyses were conducted with demographic covariates entered into the first block, maternal depression, infant difficulty perceptions, and social-marital support entered in the second block, and a different interaction term entered into the third block of each analysis. None of the interactive terms were found to be significant.

Parents who lack a sense of efficacy in their own ability to parent seem to be unable to put knowledge of parenting tasks into action, become preoccupied with themselves, often experience high levels of emotional arousal, and do not show persistence in parenting (Grusec et al., 1994). This characterization of parents who exhibit poorly established beliefs in their own competencies within the domain of parenting is congruent with Bandura's general conceptualization of selfefficacy. Bandura (1982) has proposed that when confronted with stress, individuals with low estimations of personal efficacy tend to give up easily (presumably due to failure expectancies), internalize failure, and experience pronounced anxiety and depression, as well as diminished role satisfaction.

Given the above research and theoretical support for the crucial role that maternal selfefficacy beliefs are likely to play in many dimensions of parental competency occurring across both affective and behavioral levels of maternal functioning, it is essential for researchers to discern the processes that contribute to the development of self-efficacy. 


\section{The Development of Maternal Self-Efficacy Beliefs}

Significant evidence seems to suggest that parental self-efficacy beliefs arise, at least in part, from childhood experiences (Grusec et al., 1994). Parents bring internal representations of relationships with them into the experience of parenting. Noted researchers believe that "cognitive maps" or cognitive structures that "represent regularities in their patterns of interpersonal relating" (Grusec et al., 1994, p. 9) are influential in guiding behavior in the parental domain (Bugental, 1991; Grusec et al., 1994). This approach to understanding the development of parenting self-efficacy essentially focuses on the impact of general beliefs dealing with one's relation to others. The process through which relationship schemas take form has been most thoroughly researched in the attachment literature (Ainsworth, Blehar, Waters, \& Wall, 1978). Attachment theorists view relationship schemas as working models, because schemas are construed to be gradually constructed over the course of development, and they are also believed to be activated regularly in the processes of interpreting environmental events and guiding behavior.

Attachment theory identifies three distinct models of relationships (secure, avoidant, and resistant) that emerge as a result of the quality of primary caregiver-child relationships (Ainsworth et al., 1978). These early prototypes of relationships are believed to direct behavior across the life course. Three primary patterns of adult attachment have been identified and they are believed to parallel infant styles (Main \& Goldwyn,1991, cited in Bakermans-Kranenburg \& van IJzendoorn, 1993). Adults classified as "secure-autonomous" value close relationships, but are able to exercise objectivity in evaluating their own experiences. Adults classified as "dismissive" show a tendency to limit the influence of attachment relationships in their thinking, feeling, and behavior; while making superficial claims of normalcy, strength, and independence. Finally, adults identified as "preoccupied" with early attachments lack objectivity and demonstrate substantial confusion in their descriptions of early relationships. Although very few studies have examined the association between adult attachment and maternal self-efficacy, Deutsche, Ruble, Fleming, Brooks-Gunn and Sanger (1988) found that among pregnant women, 
as the qualitative nature of women's reported relationships with their own mothers became more positive, women were more inclined to report possessing adaptive parenting skills in addition to expressing more self-confidence about the prospect of becoming a mother. Likewise, Schneewind (1995) found that $27 \%$ of the variance in young fathers' parenting efficacy and $18 \%$ of the variance in young mothers' parenting efficacy could be explained by family-of-origin variables such as quality of parenting and closeness to parents.

A second possible avenue of influence on the emergence of mothers' personal efficacy beliefs is the actual experiences mothers have with children, both encounters with their own children and with the children of relatives and community members. Goodnow (1985) argues that feedback from parent-child interactions is a primary source of competency information, and therefore should exert considerable influence on parents' perceptions of their abilities to deal effectively with the challenges of parenting. There is considerable research support for this position, stemming primarily from studies that have examined levels of parental self-efficacy in families with children who are inherently difficult to control due to temperamental qualities (Teti \& Gelfand, 1991) or behavior disorders, such as Attention Deficit Hyperactivity Disorder (Mash \& Johnson, 1983). Generally these studies have found lower levels of personal efficacy among parents with atypically demanding children when compared to parents of nonproblem children. Interestingly, the self-efficacy of parents with difficult children tends to decrease as their children grow older; while the self-efficacy of parents of nonproblem children tends to show increases corresponding to child age (Mash \& Johnson, 1983). Studies examining the relationship between maternal experience with other people's children and self-efficacy have been limited. Although Pridham and Chang (1992) found no relationship between the variables, Coleman and Karraker (unpublished manuscript) did observe a relationship between mothers' experience with children other than their own and parenting self-efficacy in mothers of elementary school age children. Literature pertaining to the relationship between parity and self-efficacy is likewise limited; however, Coleman and Karraker (unpublished manuscript) found a relationship between the variables. Despite the somewhat limited research in this area, the idea of maternal self-efficacy 
perceptions developing as a result of direct experience is congruent with Bandura's (1989) contention that the most powerful determinant of self-efficacy beliefs is often actual experiences with the referent behaviors.

\section{Measurement of Parenting Self-Efficacy Beliefs}

Most of the literature on self-efficacy relative to diverse domains of human functioning has been conducted within a Bandurian framework, with self-efficacy beliefs viewed as pertaining to the very specified requirements and dimensions of referent tasks occurring in a particular context. Bandura (1989) conceptualizes self-efficacy as an integral component of a dynamic, emergent system subject to modification in response to the changing demands of the task, situational determinants, and individual developmental processes. Although specificity of selfefficacy beliefs is central to Bandura's formulation of self-efficacy, he does acknowledge the possibility of self-efficacy beliefs operating in a more global manner under certain circumstances. Bandura does not, however, contend that self-efficacy beliefs generalize between conceptually unrelated domains.

Examination of the parenting self-efficacy research reveals substantial variability in the conceptualization and measurement of this construct. Four distinct formulations of self-efficacy have been delineated in the literature. First, the task-specific approach focuses on parents' perceptions of their own competency related to discrete tasks within the domain of parenting (e.g., identifying physical illness in one's child or providing particular forms of recreation for one's child; Ballenski \& Cook, 1982; Teti \& Gelfand, 1991). The second approach, termed domain-specific, involves simply combining data generated from task-specific measures of selfefficacy, which reflect various aspects of parenting, into a single composite measure (Bandura, Babaranelli, Caprara, \& Pastorelli, 1996). For example, parents might be asked to rate their perceptions of competence related to a number of discrete discipline, emotional nurturance, and physical care behaviors. Then the efficacy information derived from the individual task-specific items is combined to create a multidimensional index of domain level parenting self-efficacy. 
In the third approach, known as the domain-general method, parenting self-efficacy is viewed as conceptually distinct from self-efficacy in other domains; however, assessment is based on global competency expectations that are not linked to particular parenting tasks (Abidin, 1986; Dumka, Stoerzinger, Jackson, \& Roosa, 1996; Wells-Parker et al., 1990). For example, instruments utilizing this approach may examine agreement with statements such as "I am doing a fine job as a parent."

Finally, several researchers have substantially departed from Bandura's original definition of self-efficacy as pertaining to highly task-specific competency beliefs and have adopted a trait approach to general self-efficacy (Harter, 1978; Shelton, 1990; Sherer \& Adams, 1983; Tipton \& Worthington, 1984). According to this perspective, general self-efficacy represents a relatively stable personality trait with broad applicability to diverse domains, including parenting, among others. General self-efficacy is typically conceptualized as the totality of self-efficacy beliefs over the individual's entire history of achievement experiences (Watt \& Martin, 1994). An example of an item designed to tap into general self-efficacy is: "I am always certain that the plans that I make will work out."

The dominant approach to measuring parenting self-efficacy has been the use of domaingeneral measures. However, as suggested by Bandura (1989), domain-specific measures of selfefficacy, when compared to more global assessments, are likely to garner more precision in terms of the relationship between self-appraisals and actual behavior. Indeed, a substantial literature attests to the superior predictive validity of task-specific over global measures of self-efficacy (Beck \& Lund, 1981; Earley \& Lituchy, 1991; Lachman \& Leff, 1989; Multon, Brown, \& Lent, 1991; Pajares \& Miller, 1995; Wang \& Richarde, 1988). In addition, Bandura (1989) has noted that specification of causal structures or the patterning of variables linking self-efficacy beliefs to performance outcomes becomes realistic only with highly specified self-efficacy beliefs. Bandura et al. (1996) recently provided empirical support for this rationale for the use of a domain-specific measurement approach. More specifically, they found that children's selfefficacy beliefs related to different areas of competency in the school context influenced 
academic achievement through distinct mediational paths. Children's beliefs in their abilities to regulate their own learning had a direct impact on academic competence in addition to exerting indirect effects through academic aspirations, prosocial peer relations, decreased vulnerability to depression, and moral self-sanctions. Perceived efficacy to resist peer pressure to engage in maladaptive behaviors likewise had both direct and indirect effects on academic competence; however, the precise nature of the mediational paths was different.

Because most studies of parenting self-efficacy use only one measurement strategy, very little is known about how assessments of parenting self-efficacy beliefs based on discrepant conceptualizations differentially predict parent and child behavior. Therefore, measures of both domain-specific and domain-general parenting self-efficacy beliefs were purposely included in this study to enable exploration of possible differences in the relative predictive strengths associated with the two measurement strategies. Also of interest was examination of possible differences in the mediational power of self-efficacy beliefs based on different assessment strategies. Although research outside the parenting area clearly provides evidence supportive of the notion that self-efficacy beliefs measured at the task-specific level would operate as a superior predictor of parenting competence and child outcomes, a formal hypothesis relative to this expectation was not formulated due the lack of previous data specific to the parenting domain. Nevertheless, the researcher did expect better the domain-specific measure to yield more predictive power than the domain-general index.

Several instruments that measure parenting self-efficacy at the domain-general level are available (Abidin, 1986; Dumka, Stoerzinger, Jackson, \& Roosa, 1996; Wells-Parker, 1990) as are measures of general self-efficacy (Shelton, 1990; Sherer \& Adams, 1983). Unfortunately, domain-specific parenting self-efficacy measures that incorporate Bandura's conceptualization of a multidimensional approach to domain-level assessment are very scarce in the available literature. In fact, an exhaustive review of the extant research revealed only Teti and Gelfand's (1991) Maternal Efficacy Questionnaire, developed primarily for use with parents of infants, and Bandura’s (1996) unpublished Multidimensional Scales of Perceived Self-Efficacy, which 
contain the Parenting Self-Efficacy Scale, designed for use with parents of school age children. Therefore, a new task-specific measure of parenting self-efficacy suitable for administration to parents of toddlers was constructed for this study.

The research reviewed earlier clearly suggests that efficacious parents experience a sense of personal empowerment in their parental role which facilitates the management of the varied tasks of parenting, while often fostering enjoyment in the process. An efficacious parental outlook should also facilitate both intrinsic interest in parenting and commitment to the process (Bandura, 1995). On the opposite end of the spectrum, inefficacious parents tend to feel overly burdened by their parental responsibilities, frequently becoming immobilized by the emotional and physical tasks of parenthood. A few studies have suggested a negative relationship between parenting self-efficacy and child maladjustment in the domains of socio-emotional development (Donovan \& Leavitt, 1985; Swick \& Hassell, 1990) and achievement (Elder, Eccles, Ardelt, \& Lord, 1995). Nevertheless, the direct and indirect ramifications of deficiencies in parental perceptions of competency for child social, affective, and cognitive development remain largely unexamined, and represent an important goal of the present study. The available data indicate that subjective perceptions of competency are strong predictors of the objective quality of parenting behavior; and parental behavior has been demonstrated to have an impact on the emotional and intellectual growth of children in addition to meaningfully affecting the overall quality of child rearing environments (Strand \& Wahler,1996). The extent to which self-efficacy beliefs operate as a unifying construct in the parenting experience was explored in this study. Statement of the Research Problem

As indicated by the literature reviewed above, a wide range of parental variables including, among others, emotional availability, nurturance, contingent responsiveness, level of engagement or interest in parenting, efforts to cognitively stimulate and teach one's child, and the quality of play have been associated with the nature of socio-emotional and cognitive outcomes in children. Moreover, the rapidly expanding parental cognitions literature has revealed that self-efficacy beliefs, specific to the domain of parenting, represent a potent variable for explaining individual 
differences in global indexes of parenting quality. However, few existing studies have examined the relationship between self-efficacy beliefs and parental competency behaviors among parents of toddlers. Therefore, the first objective of this study was to examine the degree to which parenting self-efficacy beliefs in mothers of toddlers are related to overt measures of competence in parenting.

Very little empirical attention has been devoted to studying maternal self-efficacy beliefs as potentially useful predictors of individual differences in young children's development over various domains of functioning. Therefore, a second objective of this study was to extend the parenting self-efficacy research beyond measures of overt parental competence to assess the degree to which maternal self-efficacy beliefs likewise operate as effective predictors of specific indexes of toddlers' behavior and development.

Previously cited research conducted with mothers of infants has revealed that maternal selfefficacy operates as a powerful mediator between various psychosocial variables (e.g., sociodemographic status, infant temperamental difficulty, social support, and depression) and maternal parenting competence (Cutrona \&Troutman, 1986; Teti \& Gelfand, 1991). With selfefficacy beliefs explaining relationships between several predictor variables and parenting quality, the evidence suggests that diverse psychosocial variables do not directly impair parental functioning, but do so indirectly by undermining competency perceptions. This finding provides important clarification of at least one means through which certain infant, maternal, and contextual factors conceivably influence parenting quality. No previous research has extended investigation of this mediational role of self-efficacy beliefs to parenting of toddlers, nor have any existing studies examined possible discrepancies in the mediational strength of self-efficacy beliefs measured at different levels of analysis. Therefore, the final objective of this study was to investigate the degree to which maternal self-efficacy beliefs, assessed at the domain-specific and domain general levels, possibly mediate relationships between toddler temperament and maternal variables (child care experience and attachment to their mothers) and measures of parenting competence, satisfaction, and parenting stress. Toddler temperament, mothers' prior 
child care experience, and the quality of mothers' attachment to their own mothers were chosen for study in light of the previously reviewed literature pertaining to variables likely to play a role in the development of parental self-efficacy beliefs.

Specific hypotheses derived from a review of the available literature and the three objectives are delineated below.

1) Domain-specific parenting self-efficacy beliefs and domain-general self-efficacy beliefs were expected to operate as significant predictors of maternal competence in the parenting of toddlers.

2) Domain-specific parenting self-efficacy beliefs and domain-general parenting self-efficacy beliefs were expected to operate as significant predictors of toddler developmental and behavioral outcomes.

3) Parenting self-efficacy beliefs (assessed at both the domain specific and domain general levels) were expected to mediate the relationships between toddler temperament, maternal experience with children, mothers' attachment relationships to their own mothers and competence in parenting, parenting satisfaction, and stress associated with the parenting role.

Method

\section{$\underline{\text { Subjects }}$}

Forty-two mother-toddler pairs from Harrisonburg, Virginia participated in this study. Participants were identified primarily through examination of birth announcements listed in the local newspaper between the months of March and October 1996. Advertisements also were posted in daycare facilities, physician's offices, elementary schools, and retail stores throughout the area. 
The toddlers were between 19 and 23 months old when testing occurred, with the average toddler age being 20.9 months. The percentages of toddlers who were 19, 20, 21, 22, 23 months of age at the time of testing were $29 \%, 17 \%, 14 \%, 14 \%$, and $26 \%$ respectively. Twenty-two of the toddlers were male (53\%) and $20(47 \%)$ were female. Diversity in terms of ethnicity and socio-economic status was sought; but was unfortunately not obtained due to the predominantly White, middle-class population of Harrisonburg and the surrounding areas. Specifically, 41 $(98 \%)$ of the mother-toddler dyads were White and 1 (2\%) was Black; and the average gross annual family income was in the $\$ 41,000$ to $\$ 50,000$ range. Income did, however, range from $\$ 10,000$ to over $\$ 100,000$, with the majority (74\%) reporting incomes between $\$ 21,000$ and $\$ 60,000$. The average number of years of mothers' formal education was 15 , with a range extending from 8 to 20; $17 \%$ indicated some college experience and $45 \%$ reported having completed a bachelor's degree. Mothers' ages ranged from 22 to 39, with a mean of 31.64. Thirty-eight (90\%) of the mothers were married for the first time and 4 (10\%) were married for the second time. None of the participants were single, separated, or divorced. Fifteen of the mothers $(36 \%)$ only had the one child; $16(38 \%)$ had two children, $8(19 \%)$ had three children, and 3 mothers $(7 \%)$ had between four and six children.

Twenty-one mothers (50\%) were employed full-time; 9 (21\%) reported working part-time, and $12(29 \%)$ of the mothers were not employed outside of the home. Reported child care arrangements varied considerably: 5 of the toddlers (12\%) attended full-time daycare in a center; $15(35 \%)$ were cared for full-time in a provider's home; $1(2 \%)$ had a full-time provider in the child's home; 15 (35\%) were taken care of full-time by their mothers; 5 (12\%) spent 20 hours or fewer in a provider's home; and $1(2 \%)$ received part-time, non-maternal in-home child care. Finally, when asked how much previous experience the women had with children other than their own, $2(5 \%)$ reported none, $11(26 \%)$ reported very little, $15(36 \%)$ indicated a moderate amount, and 14 (33\%) reported having had very much experience. 


\section{Instruments}

Demographic questionnaire. The subjects were asked to provide some basic background information pertaining to their age, ethnicity, education level, annual income, employment status, marital status, number of children, and level of prior experience with children. In addition, the participants were asked about their children's day care history, toilet training, age of onset of walking, and age of first words. A copy of the demographic questionnaire is provided in Appendix A.

Domain-specific parental self-efficacy. The Maternal Efficacy Questionnaire (MEQ; Teti \& Gelfand, 1991) consists of nine 4-point items designed to assess mothers' self-efficacy beliefs in relation to specific areas of infant/toddler care, such as soothing the child, maintaining joint attention and interaction with the child, and performing daily routine tasks. Scores are summed to derive a total maternal self-efficacy score and the potential range of scores is from 9 to 36 , with higher scores indicative of stronger self-efficacy beliefs. In order to derive more readily interpretable scores, total scores are divided by 9 , creating a range from 1-4. Cronbach's alpha, an index of internal consistency reliability, was found by Teti and Gelfand to equal .86 for the MEQ. Concurrent validity evidence is also provided by the authors, as scores on the MEQ were shown to correlate strongly with the Sense of Competence subscale of the Parenting Stress Index (PSI; Abidin, 1990).

The Self-Efficacy for Parenting Tasks Index - Toddler Scale (SEPTI -TS) was the second measure of domain-specific parenting self-efficacy used in the current study. This 53-item scale was developed by the author of the current study in order to provide a comprehensive index of domain-specific self-efficacy for use with parents of toddlers. The dimensions of parenting represented on the scale were selected based on the most salient dimensions of toddler-caregiver relationships recently delineated by Zeanah et al. (1997) and originally formulated by Emde (1989). The SEPTI-TS is presented in Appendix B. The measure represents the only existing instrument available that uses Bandura's recommended multidimensional approach to domain level assessment for parents of children beyond the infancy period. Seven subscales compose the 
scale and they are designed to assess parents' sense of competence pertaining to the following discrete subdomains of parenting: a) emotional availability, b) nurturance, valuing the child, and empathetic responsiveness, c) protection from harm or injury, d) discipline and limit setting e) play, f) teaching, and g) instrumental care and establishment of structure and routines. Each of the items are rated on a 6-point Likert scale, with possible responses ranging from "Strongly Agree" to "Strongly Disagree." The Emotional Availability, Protection, Teaching, and Play subscales each contain 7 items, rendering the potential range of scores on these subscales from 7 to 42. The Nurturance and Instrumental Care subscales have 8 items each with the potential scores spanning from 8 to 48 . The Discipline subscale has 9 items and a possible score range extending from 9 to 54. Finally, total scores have a potential range of 53 to 318 . High scores on both the subscales and on the total scores are indicative of higher self-efficacy after several items are reverse scored. Only total scores were used in the dissertation data analyses conducted specifically to test the hypotheses. Further, in order to derive readily interpretable total scores, individual item scores were summed and divided by 53, resulting in a total score range extending from 1 to 6 , with higher scores reflecting higher self-efficacy.

Although subscale scores were not used in this dissertation, internal consistency reliability coefficients were computed to facilitate future development of the scale. The Cronbach's alpha coefficients computed for each of the subscales using the current sample were of variable magnitude: Emotional Availability $=.67 ;$ Nurturance $=.71 ;$ Protection $=.53(.63$ with item 16 removed $)$; Discipline $=.81 ;$ Play $=.92 ;$ Teaching $=.73 ;$ and Instrumental Care $=.46$ (.60 with item 51 removed). Clearly the Protection, Instrumental Care, and the Emotional Availability subscales should be revised prior to use. Cronbach's alpha coefficient for the full scale was found to equal .91 . Total scores on the SEPTI-TS were found to be significantly correlated with scores on the MEQ $(\underline{r}=.43)$, and with scores on the PSOC-Efficacy subscale $(\underline{r}=.57)$, providing preliminary construct validity evidence for the newly designed scale. A higher correlation between SEPTI-TS scores and scores on the MEQ was possibly not observed because the item content on the MEQ is targeted for mothers of infants rather than mothers toddlers. 
Domain-general parenting self-efficacy. To assess domain-general parenting self-efficacy, the 7-item Efficacy subscale of the Parenting Sense of Competence Scale (PSOC), developed by Gibaud-Wallston and Wandersman (1978, cited in Johnston \& Mash, 1989) was used. Each item on the PSOC is answered on a 6-point scale, with response options ranging from Strongly Disagree "6" to Strongly Agree "1". With a possible score range spanning from 7 to 42 , lower scores represent stronger self-efficacy. An example of an item on the Efficacy subscale is "I meet my own personal expectations for expertise in caring for my child." In order to derive readily interpretable total scores on the Efficacy subscale, individual item scores were summed and divided by the total number of items, rendering the range of potential scores on the composite measure from 1 to 6 , with higher scores reflecting higher self-efficacy. With a sample exceeding 500 subjects, Johnston and Mash (1989) have provided construct validation for the PSOC and have found the Efficacy subscale to possess sufficient internal consistency reliability (Cronbach's alpha=.76). The developers of the scale have likewise reported adequate internal consistency reliability (Gibaud-Wallston \& Wandersman, 1978, cited in Johnston \& Mash, 1989). Data generated with the current sample revealed a Cronbach's alpha coefficient of .81. Although this scale has primarily been used with parents of older children, the content of the items is general enough to be useful for parents of infants/toddlers.

Difficult toddler temperament. Difficult toddler temperament was measured using Bates, Freeland, and Lounsbury's (1979) Infant Characteristics Questionnaire (ICQ). This instrument measures parents' perceptions of the toddler in the context of 32 items measured on a 7-point scale, with potential scores ranging from 32 to 224 and lower scores indicative of less difficult temperament. As with other measures employed in this study, total scores were summed and divided by 32 in order to derive more readily interpretable total scores falling on a scale from 1 to 7, with higher scores reflecting more difficult child temperament. An example of an item is "How easy or difficult is it for you to predict when your baby will go to sleep and wake up?" Bates et al. (1979) have indicated that the factor structure, internal consistency, and test-retest 
reliability attest to the soundness of the instrument for research purposes. With the current sample, Cronbach's alpha coefficient for the ICQ was found to equal .89.

Quality of maternal attachment. The Inventory of Parent and Peer Attachment (IPPA) developed by Armsten and Greenberg (1987) was used to assess mothers' self-perceptions of the degree of mutual trust, quality of communication, and the extent of anger and alienation within the context of participants' current relationships with their mothers. Although the authors of the measure describe the purpose of this instrument to be to assess adolescents' perceptions of the positive and negative affective/cognitive dimension of relationships with their parents and peers, personal correspondence with Mark Greenberg in December of 1997 suggested that the instrument was potentially useful for administration to adult women. The instrument consists of three separate scales to assess individuals' levels of attachment to their mothers, fathers, and peers; however, only the Mother scale was of interest in this study. There are 25 items composing the 5-point Likert-type Mother scale, with potential scores ranging from 25 to 125 after reverse scoring of several items. After dividing total scores by 25 , the range of total scores was from 1 to 5, with higher scores suggestive of more secure attachment. Response options range from "almost never true or never true" to "almost always true or always true," and higher scores are indicative of more positive attachment. The following is an example of an item on the Mother scale: "If my mother knows something is bothering me, she asks me about it."

Cronbach's alpha coefficient for the Mother scale was reported by the authors to equal .87 , and was found to equal .95 with the present sample. Test-retest reliability for the original version, which examined attachment to mother and father in the context of one scale, was found to equal .93 with a three week interval between administrations. Although concurrent validation studies have all been conducted with adolescent samples, scores on the measure have been found to be positively associated with measures of self-esteem, life-satisfaction, and affective status (Armsden \& Greenberg, 1987). Factor analytic work with college students suggested three factors corresponding to the components of attachment described above. However, strong intercorrelations among the factors indicated that the factors were not independent, justifying 
conceptualization of the instrument as a unifactorial measure, appropriate for measuring aspects of security-insecurity along a single dimension.

Parenting satisfaction. To assess parenting satisfaction, the Satisfaction subscale of the PSOC, described above, was used. For this six point, 9-item measure, Johnston and Mash (1989) report Cronbach's alpha to be .75; and Gibaud-Wallston and Wandersman (1978, cited in Johnston \& Mash, 1989) found it to be equal to .83. With the current group of participants, Cronbach's alpha was found to equal .70. The format of the items is identical to that of the Efficacy subscale and an example of a reverse scored item is "Sometimes I feel like I'm not getting anything done." On this measure, total scores may range from 9 to 54; however once again total scores were divided by the total number of items ( 9 in this case) to create total scores ranging from 1 to 6 , with higher scores reflecting a greater level of satisfaction with being a parent.

Perceived stress. The Parenting Stress Index (PSI; Abidin,1990) was used to assess the level of stress experienced by mothers in relation to their roles as parents and relative to their perceptions of their toddlers. The inventory consists of 120 items that are answered on a 5-point Likert scale. Potential scores in their original form range from 120 to 600; however after dividing by 120 (the number of items on the scale) total scores fall on a continuum from 1 to 5 . Higher scores are associated with higher levels of perceived stress associated with raising a particular child, rather than a greater number of stressful events. A few examples of items on the PSI include "Leaving my child with a babysitter is usually a problem" and " My child generally wakes up in a bad mood." Abidin reported in the manual that the PSI possesses excellent psychometric properties. Content, concurrent, discriminant, and predictive validity evidence have been provided, and an internal consistency coefficient of .95 was achieved with the normative sample of 534 parents. Internal consistency reliability, employing Cronbach's alpha, was found to equal .93 for the current sample.

Assessment of toddler and caregiver behaviors. Quality of parenting and various indexes of toddlers' behavior were assessed using the Crowell Procedure, which was first described by 
Crowell and Feldman (1988) as an adaptation of the Matas, Arend, and Sroufe (1978) "tool use task," and was more recently outlined in detail by Zeanah et al. (1997). Caregivers are given a detailed visual and verbal orientation beforehand and the procedure consists of nine separate episodes of varying duration designed to elicit a wide range of caregiver and toddler behaviors. In the original procedure a telephone is placed in the room and the mother is called at each transition point with verbal instructions for the next step. However, for the current study, written instructions were provided to the mothers on 4" by 6" index cards and there was a clock in the room to enable them to keep track of the time for each segment as necessary. The nine episodes in order of presentation include the following: 1) unstructured free play with a number of toys, 2) clean-up, 3) play with bubbles, 4-7) teaching tasks of increasing difficulty, 8) brief separation from the caregiver, and 9) reunion. During free play the mother and toddler play for 5 minutes as they normally would at home with the aid of a basket of toys containing a doll with a bottle, three puppets, a doctor's kit, two toy phones, two toy plates and food, three small dollhouse dolls, and a toy tool kit. The clean-up session consists of requesting the mother to instruct her child to return the toys to the basket, helping the child if necessary, and having the mother place the toys outside the room. During the bubble segment the mother is asked to blow bubbles and encourage her toddler to pop them. The teaching tasks selected included completion of a puzzle, placing toy passengers into a toy bus, building a tower of 6 blocks, and operating a pop-up toy. All of the episodes outlined above were conducted; however, as recommended by Zeanah et al., only behavior observed during the first seven episodes (minus the bubbles segment) were used to assess the variables of interest in this project.

The testing room was furnished with two adult chairs, a locked cabinet for teaching task toy storage (the parent was given instructions for opening it), and three large plastic blocks that could be used as tables or turned on their sides to function as chairs. Free play toys were kept in a basket and were removed from the room following clean-up. A copy of the instructions to the mothers is provided in Appendix C. 


\section{Coding of Maternal Behavior}

The Crowell Procedure enables measurement of two broad dimensions of parenting quality: Supportive Presence and Quality of Assistance. Each of these domains are composed of two major criteria and several sub-criteria; however, only the scores on the two composite variables were employed for the purpose of this dissertation. The major and sub-criteria composing the Supportive Presence and Quality of Assistance variables are presented in Table 1. Table 1 also provides a list of the sub-criteria that are incorporated into the scoring of each of the major criteria, which is explained more fully below.

Table 1

Overview of maternal behaviors coded using the Crowell Procedure

\begin{tabular}{|c|c|c|c|}
\hline Variable & Sub-Criteria & Major Criteria & $\begin{array}{l}\text { Subcriteria used } \\
\text { in scoring of } \\
\text { Major Criteria }\end{array}$ \\
\hline \multirow{10}{*}{$\begin{array}{l}\text { Supportive } \\
\text { Presence }\end{array}$} & 1. Focusing the child on the task & Secure Base - Reflects & $2,3,4,6,7,8,9$ \\
\hline & when needed & mothers Efforts directed & \\
\hline & 2. Tuning the child in to the & feel comfortable with the & \\
\hline & $\begin{array}{l}\text { 3. Mood setting for a task } \\
\text { situation as needed }\end{array}$ & $\frac{\text { Mother Involvement }}{\text { Attentiveness to the child }}$ & $1,5,6,7,8$ \\
\hline & $\begin{array}{l}\text { sense of having completed the task } \\
\text { by him/herself }\end{array}$ & & \\
\hline & $\begin{array}{l}\text { 5. Sharing in the joy of the } \\
\text { situation }\end{array}$ & & \\
\hline & $\begin{array}{l}\text { 6. Encouraging and supporting } \\
\text { the child's efforts. }\end{array}$ & & \\
\hline & $\begin{array}{l}\text { 7. Physical presence when } \\
\text { needed. }\end{array}$ & & \\
\hline & $\begin{array}{l}\text { 8. Anticipating Frustration and } \\
\text { taking action to help the situation }\end{array}$ & & \\
\hline & $\begin{array}{l}\text { 9. Interpretation of the child's } \\
\text { behavior }\end{array}$ & & \\
\hline
\end{tabular}


Quality of 1. Defining the task
Assistance

2. Giving space initially

3. Clarity of instructions

4. Grading of hints

5. Flexibility, changing instructions as needed

6. Pacing of instructions

7. Timing of instructions

8. Cooperation - giving hints the child needs

9. Control of the situation

10. Helpful, not distracting

11. Effectiveness of instruction.

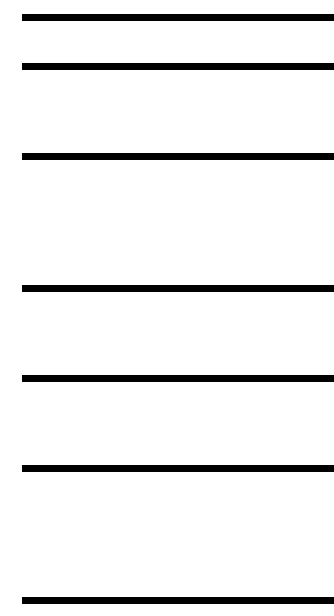

Helping the child understand and complete the task -relates to the qualitative nature of the structure which the mother applies to help the child understand that there are a series of tasks, what they are, and how to complete them.

Minimal Assistance -the degree to which the mother assists her child in such a way that the child stays interested and motivated while allowing a maximum amount of exploration and success in the task.
$2,4,7,8,9$

$1,2,3,4,5,8$ 10,11

\section{ing}

$\underline{\text { Sub-Criteria Scoring }}$

The maternal subcriteria are rated on a 3-point, behaviorally anchored scale. Table 2 provides an example illustrating the format of the coding rubrics used for scoring the subcriteria.

Table 2

Focusing the child on the task coding rubric

Score Maternal Behaviors


$1=\mathrm{No}$

$2=$ Minimal
The mother makes weak, unsuccessful, or no attempts to re-interest the child in the tool when off task behavior appears. She does not seem to realize that off-task behavior will not lead to a solution or seems too tired or disinterested to bother. Or, she seems to feel it is not worth the struggle it will involve.

The mother is slow to take action to re-interest the child in the task or in a more profitable aspect of the task. She may also seem inconsistent in her attempts to refocus the child, sometimes doing it appropriately while being slow or unresponsive at other points

Mother reinforces and re-interests the child in working on the task if the child begins to engage in off-task behavior. She is able to distinguish between on- and off-task behavior and minimizes the off-task time.

Separate subcritera scores are assigned for the behavior observed in each of the episodes;

however an overall score is also calculated based on an average (to the nearest whole number) of the scores derived from each of the episodes.

\section{Major Criteria Scoring}

Scoring of the two major criteria that fall under the Supportive Presence and Quality of Assistance variables is achieved using the same 3-point, behaviorally anchored approach that is used with the subcriteria. However, the content of major criteria anchors is based on information derived from several subcriteria as well. Table 3 provides an illustration of how the subcriteria information is incorporated into assigning scores on the major criteria.

Table 3

Secure base coding scheme

\begin{tabular}{|c|c|}
\hline Score & Maternal Behaviors \\
\hline $1=\mathrm{No}$ & $\begin{array}{l}\text { A mother who receives a "no" is unavailable to the child due to her own level of } \\
\text { frustration and inability to remain calm, her passivity, or her inability to understand the } \\
\text { child's level of capability. The mother may become angry and frustrated with the child, } \\
\text { offer absolutely nothing to let the child know it is possible to reach a solution and safe } \\
\text { to explore the toy, or she may demand that her child perform above age level and } \\
\text { expect the child to work on his/her own without encouragement. Her interpretations of } \\
\text { the child's behavior is consistently negative or incorrect and the tone of the session is } \\
\text { angry or anxious. }\end{array}$ \\
\hline
\end{tabular}


$2=$ Minimal The mother is less clearly available to the child when help or encouragement is called for. She is less able to help the child feel safe in the unfamiliar situation and with the demands of the task. She may help, but repeatedly tells the child that she can't or won't complete the task, or she refuses bids from the child. She may be slow in moving closer to the child when the child seems intimidated by the task, and may seem unaware that the child is becoming frustrated. She may not encourage and reassure the child when the child's motivation drops or frustration builds. In fact, she may occasionally misinterpret this behavior in a negative light. It may not be clear that she believes she can help the child solve the problem and seems a bit overwhelmed. The tone of the session can be one of mild anxiety.

$3=$ Yes $\quad$ A mother provides a secure base for her child by setting a calm and confident tone for the task situation. She is comfortable in the situation and therefore projects a sense of confidence and positive outcome. She does so by remaining calm and mood setting; she approaches the toy with interest or, even better, with enthusiasm. She makes certain that the child realizes there is a problem to be solved. By tuning, she indicates to the child that working on the activity can be rewarding. She may also indicate to the child that she is available to work cooperatively if it becomes necessary, but encourages initial autonomous work to help the child achieve a sense of completing the task by him/herself.

In addition to deriving major criteria scores for the individual episodes, an overall score is calculated for each of the four major criteria based on an average (to the nearest whole number) of the separate episode scores.

Scoring of Supportive Presence and Quality of Assistance

Finally, total scores for each of the two primary global variables (Supportive Presence and Quality of Assistance) are derived using anchor points ranging from 1 to 7, with higher scores indicative of more positive parenting behavior. In this case, the content of the anchors is based on the coding derived from both the overall subcriteria and major criteria scores. Appendix D provides the anchor points for the ratings of the Quality of Assistance and Supportive Presence variables. Finally, Appendix E provides a template of the coding sheets that were used to score the subcritera, major criteria, and the Supportive Presence and Quality of Assistance variables. Although individual major and subcritera scores are calculated for the maternal behavior observed in each of the six episodes, only one Supportive Presence and Quality of Assistance score is assigned based on the information obtained across all segments. As an index of inter- 
rater agreement, Crowell and Feldman (1988) reported kappa coefficients of .87 and .94 for the Quality of Assistance and Supportive Presence variables respectively.

Coding of Toddler Behaviors

The Crowell Procedure also allows for the assessment of several toddler behaviors rated on a scale of 1-7 in the six segments. An overall score based on information across all of the individual segments is also derived for each behavior. Only these overall scores were used in the dissertation data analyses. In each case, higher scores are indicative of higher levels of the variable observed. An overview of the behaviors specifically examined in this study is presented in Table 4. As an index of inter-rater agreement, Crowell and Feldman (1988) reported kappa coefficients ranging from .68 to 1.0 on the toddler behavior variables. Appendix F provides an illustration of the coding format used for one of the child behaviors, and Appendix G provides a template of the coding sheets that were used to score various child behaviors.

Table 4

Crowell Procedure toddler variables

\begin{tabular}{ll}
\hline Child Behavior & Description \\
\hline Enthusiasm & $\begin{array}{l}\text { The degree to which the child acts with vigor, } \\
\text { confidence, and eagerness to perform the tasks. } \\
\text { The enthusiastic child takes an active interest } \\
\text { in his/her activities and invests effort in them. }\end{array}$ \\
\hline Compliance & $\begin{array}{l}\text { The degree to which the child follows the } \\
\text { mother's task directions. }\end{array}$ \\
\hline Avoidance of mother & $\begin{array}{l}\text { A measure of the extent to which the child was } \\
\text { problem-oriented in the session. }\end{array}$ \\
\hline Affection towards mother & $\begin{array}{l}\text { The child's tendencies or clear attempts to } \\
\text { avoid interacting with the mother. }\end{array}$ \\
& $\begin{array}{l}\text { The extent to which there was a substantial } \\
\text { period of positive regard and exchange of } \\
\text { happy feelings directed by the child toward the } \\
\text { mother. }\end{array}$
\end{tabular}


Experience of the session
The degree to which the child's experience in the testing situation probably resulted in feelings of success and competence on the tasks and confidence in having a good relationship with his/her mother.

The degree to which the child shows anger, dislike, or hostility toward the mother.

Previous research employing the Crowell Procedure has revealed a significant relationship between assessments of mothers' behavior observed during the procedure and measurement of their internal models of relationships (Crowell \& Feldman, 1988). Further, studies have demonstrated significant associations between toddler behaviors coded during use of the procedure and various indexes of toddlers' developmental and behavioral status (Matas et al., 1978; Crowell \& Feldman, 1988).

Child Developmental Status. The Bayley Scales of Infant Development (BSID-II; Bayley, 1993), an individually administered test designed to measure the current developmental status of children ranging in age from 1 to 42 months, was used to determine the toddlers' levels of cognitive, language, and social development. Three scales including the Mental Scale, Motor Scale, and the Behavior Rating Scale (BRS) compose the BSID-II. Information yielded from the Mental and Motor Scales includes the child's present level of cognitive, language, personal-social, and motor development. More precisely, items included on the Mental Scale tap into memory, problem solving, numerical concepts, generalization, classification, expressive and receptive language, and social skills. The Motor Scale, which assesses both fine and gross motor development, includes items pertaining to the use of writing utensils, imitation of hand movements, walking, running, and jumping. The primary purpose of the BRS is to assess child behavior during the course of testing in order to guide appropriate interpretation of performance on the Mental and Motor Scales. The BRS subscales appropriate for administration to toddlers include the following: Orientation/Engagement toward the tasks, examiner, and caregiver, Emotional Regulation, and Quality of Movement. Although 178 items constitute the full Mental Scale and 111 items are on the entire Motor Scale, age-appropriate item 
sets have been developed with approximately 25-50 Mental and Motor items on each. Raw scores are converted to a Mental Development Index (MDI) and a Psychomotor Development Index (PDI). On both indexes, scores above 115 are considered indicative of accelerated performance, scores ranging between 85 and 114 are within normal limits, scores between 70 and 84 are in the mildly delayed range, and finally, scores of 69 or lower are suggestive of significantly delayed performance. The mean and standard deviation for both MDI and PDI scores are believed to be 100 and 15 respectively. According to the test developers (Bayley, 1993), the BSID-II possesses internal consistency, test-retest, and inter-rater reliability in addition to content, construct, predictive, and discriminant validity. Only data derived from the BSID-II Mental Scale (MDI scores) were used in the dissertation data analyses.

\section{$\underline{\text { Procedure }}$}

Names of mothers with appropriate age children were obtained from old newspaper announcements, and those with current addresses were mailed a brief description of the study. Approximately 10 days after the letters were mailed, the women were called, more information about the study was provided (time required, procedural details, and a general description of the purpose and utility of the research), and the women were asked if they were interested in participating. Interested mothers were then mailed informed consent forms, which assured them of the confidentiality of their responses, along with a pre-addressed and stamped return envelope. After one copy of the informed consent form was returned, the experimenter contacted each participant and arranged for a 2-hour laboratory assessment during a time of day when mothers anticipated that their children would not be very tired. Approximately two weeks prior to the scheduled visit, a packet of questionnaires was mailed to each participant with instructions to bring the completed forms to the scheduled laboratory appointment. These questionnaires assessed demographic information, level of experience with children, two forms of parenting self-efficacy, the quality of mothers' relationships with attachment figures, difficult child temperament, parenting satisfaction, and stress associated with the parental role. Mothers indicated that the total time required to complete these measures generally did not exceed 1 hour. 
The session began with administration of the Bayley Scales to the toddlers, with mothers holding their children on their laps throughout the testing. The experimenter has been sufficiently trained to reliably give the test. Testing took approximately 45 minutes and was followed by a brief (5-10 minute) break period during which mothers were encouraged to rest and relax in a room with reading material and toys available. Observational assessment of parental and child behaviors using the Crowell Procedure followed the break period and took approximately 30 minutes to complete. Both administration of the Bayley Scales and the Crowell Procedure were videotaped. Although scoring of the Bayley occurred as the toddlers were tested, the videotape enabled verification of correct scoring. Video-taping of the Crowell procedure was necessary to facilitate subsequent coding by two objective raters and determination of inter-rater reliability.

Following participation in the study, subjects were graciously thanked, offered the opportunity to receive a copy of the results of the study, and were given a small commemorative token of appreciation (a developmentally appropriate toy or an article of clothing for their toddlers.)

\section{Training of Raters}

Two trained undergraduate students coded maternal and child behaviors observed during the Crowell Procedure. Training consisted of viewing a training video produced by the developers of the procedure, becoming thoroughly acquainted with the coding manual, and coding the behavior of three sample dyads provided on the training video. The students were also given ample opportunity to ask questions for clarification on the coding scheme and to share experiences prior to coding the actual study videos. Cohen's kappa statistic, an index of interrater reliability designed to correct for chance agreement, was computed for each of the composite maternal behaviors and the seven toddler behaviors coded using the training dyads. For the Supportive Presence and Quality of Assistance maternal variables kappa coefficients were found to equal 1.0 and .66 respectively and kappas for the child behaviors ranged from .66 to 1.0 as well. Based on the levels of inter-rater agreement achieved with the training dyads no further training was deemed necessary. One rater coded behaviors for all 42 mother-toddler 
dyads; whereas the second rater only coded behaviors for the first 21 dyads. Cohen's kappas were again calculated using 21 of the study dyads (50\% of the data). Kappa coefficients for the Supportive Presence and Quality of Assistance maternal variables were equal to .75 and .80 respectively. Kappa coefficients for the child behavior variables were as follows: Enthusiasm .82, Compliance .78, Persistence .70, Avoidance of mother .68, Affection towards mother .70, Experience of the session .68, and Negativity .75. According to Fleiss (1981), kappa values > .60 are considered acceptable. Because sufficient inter-rater agreement was obtained, only data coded by the rater who scored all of the dyads were used for data analysis purposes.

Results

\section{$\underline{\text { Basic Descriptive Statistics and Correlations Among the Study Variables }}$}

Table 5 provides the descriptive statistics (means, standard deviations, and score ranges) for the following variables: parenting self-efficacy (PSOC-Efficacy subscale, SEPTI-TS, and MEQ scores), satisfaction in parenting (PSOC-Satisfaction subscale), parenting stress (PSI scores), mothers' experience with children (a single self-report item), mothers' attachment to their mothers (IPPA scores), maternal behavioral competence (Supportive Presence and Quality of Assistance variables from the Crowell Procedure), toddler temperament (ICQ scores), toddler developmental status (MDI scores), and child behaviors observed during the Crowell Procedure (Enthusiasm, Compliance, Affection towards mother, Persistence, Avoidance of mother, Experience of the session, and Negativity). Parenting self-efficacy beliefs, as measured at both the domain-specific and the domain-general levels, tended to be very high for this sample of mothers. Mothers' reports of satisfaction with parenting and their attachment to their mothers were also generally very high, while stress associated with the parental role tended to be low for the group. Further, the average participant indicated a moderate level of experience with children and exhibited high levels of competency in parenting behaviors as displayed during the Crowell Procedure. The toddlers generally demonstrated positive behavior in interaction with their mothers as indicated by the group scores on the seven behavioral variables coded during the 
Crowell Procedure; and the mean and standard deviation derived from the MDI scores were nearly equivalent to those achieved with the standardization sample (Bayley, 1993).

Table 5

Descriptive statistics for study variables

\begin{tabular}{|c|c|c|c|c|}
\hline Variable & Potential Range & Observed Range & $\mathrm{M}$ & SD \\
\hline PSOC-Efficacy (domain-general) & $1.00-6.00$ & $2.29-5.86$ & 4.69 & .81 \\
\hline SEPTI-TS (domain-specific) & $1.00-6.00$ & $4.15-5.81$ & 5.11 & .42 \\
\hline MEQ (domain-specific) & $1.00-4.00$ & $2.80-3.90$ & 3.36 & .25 \\
\hline PSOC-Satisfaction & $1.00-6.00$ & $3.56-6.00$ & 4.92 & .68 \\
\hline PSI (parenting stress) & $1.00-5.00$ & $1.37-2.77$ & 2.08 & .31 \\
\hline Exper. w/children other than own & $1.00-4.00$ & $1.00-4.00$ & 98 & .90 \\
\hline Mothers' attachment & $1.00-5.00$ & $2.64-5.00$ & 4.04 & .67 \\
\hline Quality of assistance & $1.00-7.00$ & $3.00-7.00$ & 5.81 & 1.55 \\
\hline Supportive presence & $1.00-7.00$ & $2.00-7.00$ & 6.10 & 1.43 \\
\hline ICQ (difficult toddler temp.) & $1.00-5.00$ & $2.06-4.13$ & 3.14 & .54 \\
\hline Toddler enthusiasm & $1.00-7.00$ & $2.00-7.00$ & 5.59 & .92 \\
\hline Toddler compliance & $1.00-7.00$ & $2.00-7.00$ & 5.76 & 1.21 \\
\hline Toddler affection - mother & $1.00-7.00$ & $1.00-7.00$ & 5.45 & 1.23 \\
\hline Toddler persistence & $1.00-7.00$ & $2.00-7.00$ & 5.64 & 1.14 \\
\hline Toddler avoidance of mother & $1.00-7.00$ & $1.00-6.00$ & 1.93 & 1.11 \\
\hline Toddler experience of the session & $1.00-7.00$ & $2.00-7.00$ & 5.55 & .94 \\
\hline Toddler negativity & $1.00-7.00$ & $1.00-7.00$ & 1.76 & 1.14 \\
\hline MDI (BSID-II, Mental Scale) & $55.00-145.00$ & $64.00-128.00$ & 100.90 & 15.40 \\
\hline
\end{tabular}

Table 6 provides a zero-order correlational matrix with all of the primary study variables (listed above). As is apparent from examination of the data presented, moderate to strong correlations were evidenced between each pair of the child behavior variables observed. Bayley MDI scores were moderately correlated with each of the child behaviors observed during the Crowell Procedure as well. Significant strong correlations were also detected between the two indexes of maternal behavioral competence (Supportive Presence and Quality of Assistance) and the seven child behavior variables and with MDI scores. The Quality of Assistance variable was also significantly associated with mothers' reports of their levels of experience with children. Child temperament correlated significantly with the two domain-specific indexes of parenting self-efficacy and with parenting stress. Moderate correlations among the three parenting selfefficacy measures were also revealed. SEPTI-TS scores were found to be a stronger correlate of both parenting stress and parenting satisfaction than the other domain-specific index (MEQ) an 
the domain-general measure (PSOC-Efficacy). The directionality of each of these significant correlations is provided in Table 6.

Table 6

Zero-Order Correlations Among Study Variables

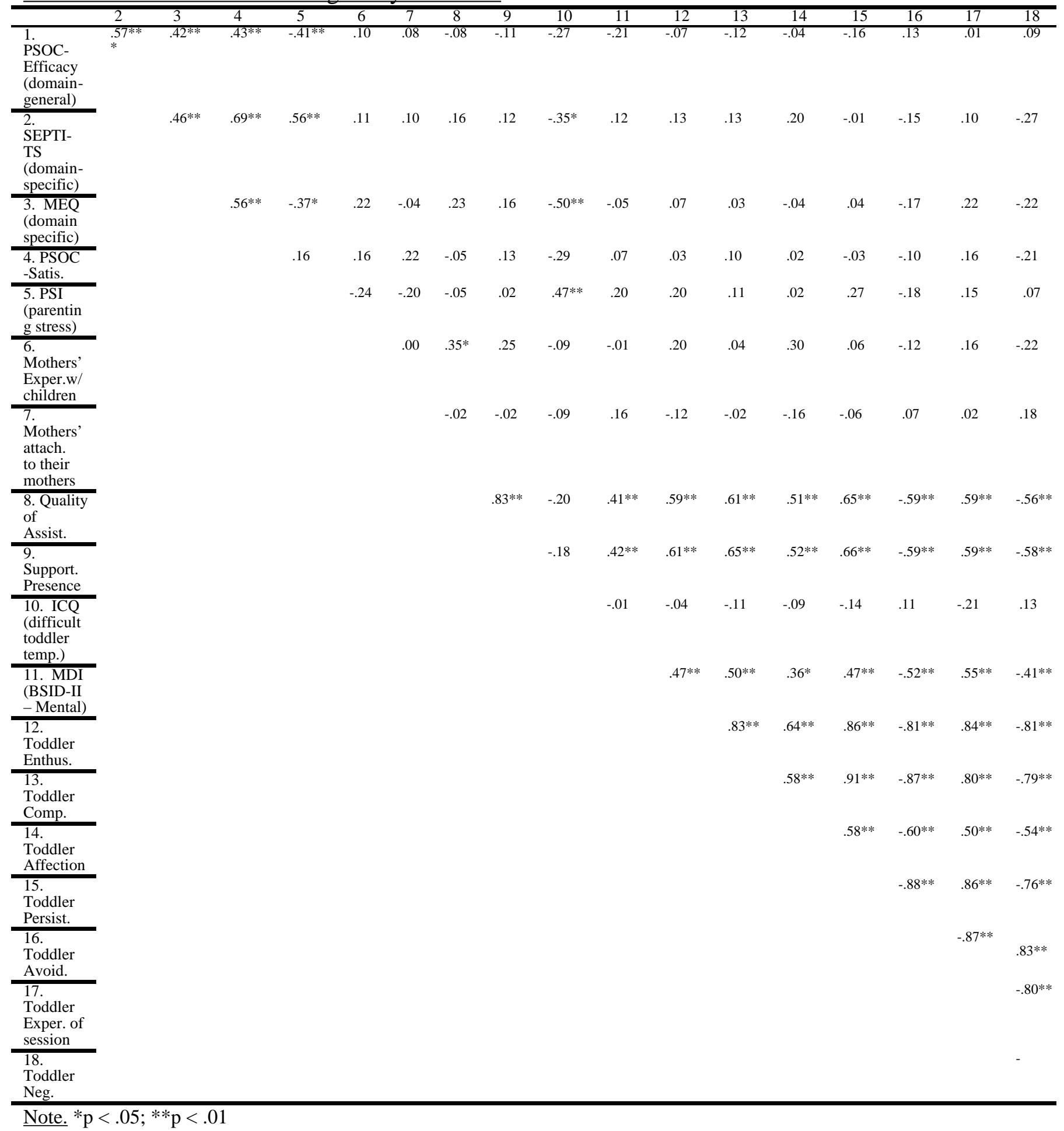


Preliminary Exploratory Analyses with Demographic Data

A number of preliminary exploratory analyses were conducted to determine whether or not any of the demographic variables were related systematically to any of the primary study variables, necessitating the introduction of possible covariates into the analyses conducted to test the hypotheses. Maternal age was found to be inversely correlated with the domain-general measure of parenting self-efficacy (PSOC scores), $\underline{\mathrm{r}}(40)=-.41, \underline{\mathrm{p}}<.01$, and positively associated with toddlers' MDI scores, $\underline{\mathrm{r}}(40)=.31, \underline{\mathrm{p}}<.05$. Therefore, maternal age was introduced as a covariate in all of the analyses conducted to test the hypotheses involving these variables. None of the remaining demographic items (maternal education, annual income, maternal employment, marital status, number of children, child age, nor child gender) were significantly related to any of the primary study variables.

\section{Parenting Self-Efficacy Beliefs as Predictors of Parenting Competence}

In order to test the first hypothesis, which predicted that task-specific and domain-general parenting self-efficacy beliefs would operate as significant predictors of maternal competence in the parenting of toddlers, two sets of regression equations were conducted with the Supportive Presence variable from the Crowell Procedure operating as the criterion in the first set of analyses and the Quality of Assistance variable serving as the criterion in the second set analyses. The original data analysis plan was to enter scores from the domain-specific self-efficacy measure (SEPTI-TS) and from the domain-general index (PSOC-Efficacy) into the same regression equation in order to test the degree to which efficacy information derived from the two distinct measurement approaches predicted parenting competence. However, the decision was made to conduct separate tests for each measure of self-efficacy, because the correlation between the two forms of parenting self-efficacy was moderately high $(\mathrm{r}=.57)$.

With Supportive Presence as the criterion and domain-specific self-efficacy beliefs (SEPTI-TS) scores as the predictor, the result was not significant, $\underline{\mathrm{F}}(1,40)=.58, \underline{\mathrm{p}}>.05, \underline{\mathrm{R}}=.12$, $\underline{r}^{2}=.01$. Domain-general self-efficacy beliefs (PSOC scores) were likewise not found to significantly predict Supportive Presence after maternal age was entered into the first block as a 
covariate, $\underline{\mathrm{F}}(2,39)=.43, \underline{\mathrm{p}}>.05, \underline{\mathrm{R}}=.15, \underline{\mathrm{r}}^{2}=.02$. When Quality of Assistance served as the criterion and domain-specific self-efficacy beliefs (SEPTI-TS) scores functioned as the predictor, the result was not significant, $\underline{F}(1,40)=1.09, \underline{\mathrm{p}}>.05, \underline{\mathrm{R}}=.16, \underline{\mathrm{r}}^{2}=.03$. Domain-general selfefficacy beliefs (PSOC scores) were similarly not found to significantly predict Quality of Assistance after maternal age was entered into the first block as a covariate, $\underline{F}(2,39)=.43, \underline{p}$ $>.05, \underline{\mathrm{R}}=.15, \underline{\mathrm{r}}^{2}=.02$.

\section{Parenting Self-Efficacy Beliefs as Predictors of Child Developmental Status and Behavior}

Two separate series of regression analyses were conducted in order to test the second hypothesis, which postulated that task-specific and domain-general parenting self-efficacy beliefs would operate as significant predictors of toddler developmental status (MDI scores) and various behavioral outcomes (seven Crowell Procedure variables). In the first set of equations, domainspecific parenting self-efficacy beliefs operated as the predictor with a different toddler variable serving as the criterion in each analysis. Domain-specific self-efficacy beliefs failed to predict any of the child outcome variables. The results of the analyses were as follows: Enthusiasm, $\underline{\mathrm{F}}(1$, $40)=.67, \underline{\mathrm{p}}>.05, \underline{\mathrm{R}}=.13, \underline{\mathrm{r}}^{2}=.02 ;$ Compliance, $\underline{\mathrm{F}}(1,40)=.65, \underline{\mathrm{p}}>.05, \underline{\mathrm{R}}=.13, \underline{\mathrm{r}}^{2}=.02$; Affection towards mother, $\underline{\mathrm{F}}(1,40)=1.74, \underline{\mathrm{p}}>.05, \underline{\mathrm{R}}=.20, \underline{\mathrm{r}}^{2}=.04$; Persistence, $\underline{\mathrm{F}}(1,40)=.00$, $\underline{\mathrm{p}}>.05, \underline{\mathrm{R}}=.01, \underline{\mathrm{r}}^{2}=.00 ;$ Avoidance of mother, $\underline{\mathrm{F}}(1,40)=.94, \underline{\mathrm{p}}>.05, \underline{\mathrm{R}}=.15, \underline{\mathrm{r}}^{2}=.02$; Experience of the session, $\underline{\mathrm{F}}(1,40)=.44, \underline{\mathrm{p}}>.05, \underline{\mathrm{R}}=.01, \underline{\mathrm{r}}^{2}=.01 ;$ Negativity, $\underline{\mathrm{F}}(1,40)=3.10$, $\underline{\mathrm{p}}>.05, \underline{\mathrm{R}}=.27, \underline{\mathrm{r}}^{2}=.07$; and MDI scores, $\underline{\mathrm{F}}(1,40)=.54, \underline{\mathrm{p}}>.05, \underline{\mathrm{R}}=.12, \underline{\mathrm{r}}^{2}=.01$.

In the second set of analyses, domain-general parenting self-efficacy beliefs served as the predictor with a different toddler variable as the criterion in each test. In order to control for the effects of maternal age, this variable was entered into the first block in all of the regression equations prior to the entry of PSOC scores in the second block. The results were similar to those obtained with the domain-specific measure as domain-general self-efficacy beliefs were not found to significantly predict any of the toddler outcome variables. The results of the analyses were as follows: Enthusiasm, $\underline{\mathrm{F}}(2,39)=.27, \underline{\mathrm{p}}>.05, \underline{\mathrm{R}}=.12, \underline{\mathrm{r}}^{2}=.01 ;$ Compliance, $\underline{\mathrm{F}}(2,39)=$ $.27, \underline{\mathrm{p}}>.05, \underline{\mathrm{R}}=.12, \underline{\mathrm{r}}^{2}=.01 ;$ Affection towards mother, $\underline{\mathrm{F}}(2,39)=.06, \underline{\mathrm{p}}>.05, \underline{\mathrm{R}}=.05, \underline{\mathrm{r}}^{2}=.00$; 
Persistence, $\underline{F}(2,39)=.82, \underline{p}>.05, \underline{R}=.20, \underline{r}^{2}=.04$; Avoidance of mother, $\underline{F}(2,39)=.58, \underline{p}$

$>.05, \underline{\mathrm{R}}=.17, \underline{\mathrm{r}}^{2}=.03$; Experience of the session, $\underline{\mathrm{F}}(2,39)=.45, \underline{\mathrm{p}}>.05, \underline{\mathrm{R}}=.12, \underline{\mathrm{r}}^{2}=.01$;

Negativity, $\underline{F}(2,39)=.44, \underline{p}>.05, \underline{R}=.15, \underline{r}^{2}=.02$; and MDI scores, $\underline{F}(2,39)=2.28, \underline{p}>.05, \underline{\mathrm{R}}$ $=.32, \underline{\mathrm{r}}^{2}=.10$.

Mediational Effects of Parenting Self-Efficacy Beliefs

In order to examine the degree to which domain-specific parenting self-efficacy beliefs (SEPTI-TS scores) operated as a mediator of the relationships between child temperament, maternal experience with children other than their own, and mothers' attachment to their mothers and parenting competence (Quality of Assistance and Supportive Presence), satisfaction, and stress associated with the role, Baron and Kenny's (1986) model and data analysis techniques for determining mediator effects were followed. Four separate sets of regression equations were conducted, with each set adopting a different criterion. Initially equations were estimated for predicting domain-specific parenting self-efficacy from child temperament, mothers' experience with children, and mothers' attachment to their mothers. For each set of analyses, equations were subsequently estimated for predicting each criterion from child temperament, mothers' experience with children, and mothers' attachment to their mothers and for predicting each criterion from each of these predictors with parenting self-efficacy entered into the equation. Mediation requires that a particular variable (child temperament, maternal experience with children, or maternal attachment) be significantly related to both parenting self-efficacy and the criterion, and that parenting self-efficacy beliefs continue to be related to the criterion with the particular child or maternal variable included in the equation. Moreover, mediation is most evident when the relationship between the child or maternal variable and the criterion is reduced to non-significance when parenting self-efficacy is included in the equation.

Table 7 provides the results of the regression equations with the Quality of Assistance, Supportive Presence, parenting satisfaction, and parenting stress variables serving as the criterion. Based on the requirements for mediation outlined by Baron and Kenny, the data suggest that self-efficacy beliefs, measured at the domain-specific level, did in fact mediate the 
relationship between child temperament and mothers' reports of stress associated with parenting. Although the effect of child temperament on parenting stress is reduced by the mediational influence of parenting self-efficacy, the relationship between temperament and parenting stress remains significant with self-efficacy beliefs entered into the equation, indicating the presence of a direct relationship between child temperament and stress associated with the parenting role as well. The data also suggest that parenting self-efficacy beliefs mediate the relationship between child temperament and satisfaction with parenting. However, because the relationship between temperament and satisfaction only approaches significance, the requirements for mediation set forth by Baron and Kenny are not strictly met. The magnitude of the relationship between temperament and satisfaction does, however, drop substantially with self-efficacy beliefs in the equation.

Baron and Kenny recommend using a formula derived by Sobel to provide an approximate significance test for the indirect effect of the independent variable on the dependent variable. Application of this formula to the relationship between toddler temperament and stress associated with the role as mediated by domain-specific self-efficacy beliefs revealed a value of .06; whereas a value of .11 was derived for the strength of the relationship between toddler temperament and parenting satisfaction as mediated by self-efficacy beliefs. 
Table 7

$\underline{\text { Regression Equations to Test for the Mediational Role of Domain-Specific Self-Efficacy in }}$ Parenting Behavior

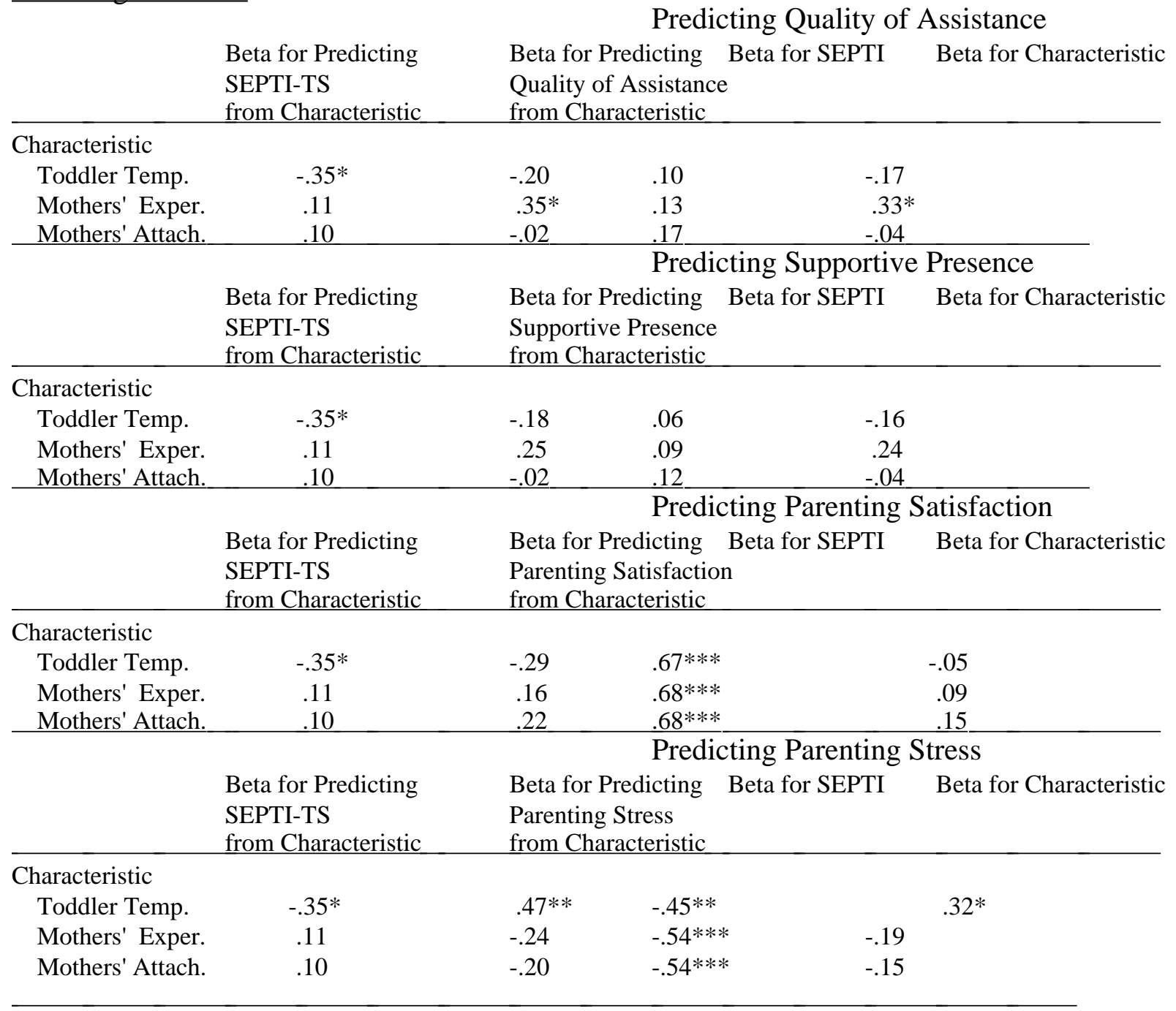

In order to assess the degree to which domain-general parenting self-efficacy beliefs operated as a mediator of the effects of child temperament, maternal experience with children other than their own, and mothers' attachment to their mothers on parenting competence (Quality of Assistance and Supportive Presence), satisfaction, and stress associated with the role, Barron and Kenny's recommended set of regression analyses were once again conducted. However, because maternal age was found to be significantly related to domain-general self-efficacy beliefs, maternal age was entered as the first variable in all of the regression analyses conducted to test for mediation of this second form of parenting self-efficacy. The results of these 
regression analyses are presented in Table 8 . As is evident from the data presented, domaingeneral parenting self-efficacy beliefs were not found to operate as a mediator of the effects of child temperament, mothers' attachment to their mothers, or maternal child care experience on parenting competence, satisfaction, or stress associated with the parenting role. 
Table 8

Regression Equations to Test for the Mediational Role of Domain-General Self-Efficacy in Parenting Behavior

Predicting Quality of Assistance w/ Maternal Age Controlled

Beta for Predicting Beta for Predicting Beta for PSOC Beta for Characteristic PSOC-Efficacy Quality of Assistance

from Characteristic from Characteristic

w/Maternal Age w/Maternal Age

Controlled Controlled

$\begin{array}{lcccc}\text { Characteristic } & & & & \\ \text { Toddler Temp. } & -.20 & -.23 & -.10 & -.25 \\ \text { Mothers' Exper. } & .12 & .34^{*} & -.10 & .35^{*} \\ \text { Mothers' Attach. } & .10 & -.03 & -.05 . & -.03\end{array}$

\begin{tabular}{|c|c|c|c|c|}
\hline & \multirow[b]{2}{*}{$\begin{array}{l}\text { Beta for Predicting } \\
\text { PSOC-Efficacy } \\
\text { from Characteristic } \\
\text { w/Maternal Age } \\
\text { Controlled }\end{array}$} & \multirow{2}{*}{$\begin{array}{l}\text { Beta for Predicting } \\
\text { Supportive Presence } \\
\text { from Characteristic } \\
\text { w/Maternal Age } \\
\text { Controlled }\end{array}$} & \multicolumn{2}{|c|}{$\begin{array}{l}\text { Predicting Supportive Presence w/ } \\
\text { Maternal Age Controlled }\end{array}$} \\
\hline & & & Beta for PSOC & Beta for Characteristic \\
\hline \multicolumn{5}{|l|}{ Characteristic } \\
\hline Toddler Temp. & -.20 & -.21 & -.11 & -.23 \\
\hline Mothers' Exper. & .12 & .24 & -.10 & .26 \\
\hline \multirow[t]{3}{*}{ Mothers' Attach. } & .10 & -.03 & -.06 & -.02 \\
\hline & & & \multicolumn{2}{|c|}{$\begin{array}{l}\text { Predicting Parenting Satisfaction w/ } \\
\text { Maternal Age Controlled }\end{array}$} \\
\hline & $\begin{array}{l}\text { Beta for Predicting } \\
\text { PSOC-Efficacy } \\
\text { from Characteristic } \\
\text { w/Maternal Age } \\
\text { Controlled }\end{array}$ & $\begin{array}{l}\text { Beta for Parenting } \\
\text { Satisfaction } \\
\text { from Characteristic } \\
\text { w/Maternal Age } \\
\text { Controlled }\end{array}$ & Beta for PSOC & Beta for Characteristic \\
\hline \multicolumn{5}{|l|}{ Characteristic } \\
\hline Toddler Temp. & -.20 & -.27 & $.42 *$ & -.19 \\
\hline Mothers' Exper. & .12 & .17 & $.44 * *$ & .12 \\
\hline \multirow[t]{3}{*}{ Mothers' Attach. } & .10 & .22 & $.43 * *$ & .18 \\
\hline & & & \multicolumn{2}{|c|}{$\begin{array}{l}\text { Predicting Parenting Stress w/ } \\
\text { Maternal Age Controlled }\end{array}$} \\
\hline & $\begin{array}{l}\text { Beta for Predicting } \\
\text { PSOC-Efficacy } \\
\text { from Characteristic } \\
\text { w/Maternal Age } \\
\text { Controlled }\end{array}$ & $\begin{array}{l}\text { Beta for Predicting } \\
\text { Parenting Stress } \\
\text { from Characteristic } \\
\text { w/Maternal Age } \\
\text { Controlled }\end{array}$ & Beta for PSOC & Beta for Characteristicls \\
\hline \multicolumn{5}{|l|}{ Characteristic } \\
\hline Toddler Temp. & -.20 & $.47 * *$ & $-.42 *$ & -.19 \\
\hline Mothers' Exper. & .12 & -.24 & $-.40^{*}$ & -.19 \\
\hline Mothers' Attach. & .10 & -.20 & $-.41^{*}$ & -.16 \\
\hline
\end{tabular}


Partial support was obtained for the third hypothesis based on the evidence for mediation detected relative to the domain-specific parenting self-efficacy measure.

\section{$\underline{\text { Secondary Analyses }}$}

Secondary analyses were conducted to see if toddlers' current day care arrangement or their use of a security object such as a pacifier or blanket was related to any of the key study variables. A few interesting findings were observed. Toddlers currently enrolled in some form of non-maternal day care $(\underline{n}=26)$ were compared to toddlers who were cared for full-time by their mothers $(\underline{n}=15)$ on the seven Crowell Procedure variables using a Multivariate Analysis of Variance. Although the overall model was not significant employing Hotellings $\mathrm{F}$ as the Omnibus test, $\underline{\mathrm{F}}(7,34)=1.38, \underline{\mathrm{p}}>.05$, several of the univariate $\mathrm{F}$ tests were significant. Table 9 provides the F statistics, the significance of each $\mathrm{F}$, and the means and standard deviations for the non-maternal care and the maternal care groups on each of the dependent variables.

Table 9

Results of Univariate F tests derived from a MANOVA with form of care as the independent variable and Crowell Procedure toddler behaviors as the dependent variables

\begin{tabular}{|c|c|c|c|c|c|c|}
\hline \multirow[t]{2}{*}{ Dependent Variable } & \multirow[t]{2}{*}{$\bar{F}$} & \multirow[t]{2}{*}{$\begin{array}{l}\text { Sig. of } \\
F\end{array}$} & \multicolumn{2}{|l|}{$\begin{array}{l}\text { Non- } \\
\text { Maternal } \\
\text { Care }\end{array}$} & \multicolumn{2}{|c|}{$\begin{array}{l}\text { Full-time } \\
\text { Maternal } \\
\text { Care }\end{array}$} \\
\hline & & & $\underline{\mathrm{M}}$ & $\underline{\mathrm{SD}}$ & $\underline{\mathrm{M}}$ & $\underline{\text { SD }}$ \\
\hline Enthusiasm & 2.73 & .106 & $\overline{5.52}$ & $\overline{1.01}$ & $\overline{6.00}$ & $\overline{.66}$ \\
\hline Compliance & 7.58 & .009 & 5.41 & 1.28 & 6.40 & .74 \\
\hline Affection towards mother & 1.22 & .277 & 5.30 & 1.10 & 5.73 & 1.44 \\
\hline Persistence & 4.67 & .037 & 5.37 & 1.25 & 6.13 & .74 \\
\hline Avoidance of mother & 5.89 & .020 & 2.22 & 1.22 & 1.40 & .63 \\
\hline Experience of the session & 6.04 & .018 & 5.29 & .99 & 6.00 & .66 \\
\hline Negativity & 4.78 & .035 & 2.04 & 1.32 & 1.27 & .46 \\
\hline
\end{tabular}

Note. $\mathrm{df}=1,40$

When toddlers using some form of security object were compared to those that who did not use one at the time of testing, a significant difference was revealed relative to the temperament variable, $\mathrm{t}(39)=2.43, \mathrm{p}<.05$. Toddlers, who did use a security object were identified by their mothers as having significantly more difficult temperament $(\underline{\mathrm{M}}=3.29 ; \underline{\mathrm{SD}}=.51)$ than their no- 
security object using peers $\underline{(\mathrm{M}}=2.89 ; \underline{\mathrm{SD}}=.50)$. Twenty-six toddlers were in the security object group and 15 were in the no-security object group.

Finally, exploratory correlational analyses were conducted to investigate the extent to which subscale scores derived from the domain-specific parenting self-efficacy measure (SEPTITS) were associated with the maternal and toddler behaviors observed during the Crowell Procedure. Examination of the coefficients presented in Table 10 reveals that only one correlation was significant.

Table 10

Zero-Order correlation coefficients for SEPTI-TS subscales and Crowell Procedure variables

\begin{tabular}{|c|c|c|c|c|c|c|c|c|c|}
\hline SEPTI-TS Subscale & Enthus. & Comp. & Affect. & Persist. & Avoid. & $\begin{array}{l}\text { Exper. } \\
\text { Session }\end{array}$ & Negat. & $\begin{array}{l}\text { Supportive } \\
\text { Presence }\end{array}$ & $\begin{array}{l}\text { Quality of } \\
\text { Assistance }\end{array}$ \\
\hline Emotional & & & & & & & & & \\
\hline Availability & .00 & .06 & .00 & -.06 & -.10 & .06 & -.20 & .10 & .11 \\
\hline Nurturance & .08 & .04 & .18 & .01 & -.13 & .10 & -.23 & .17 & .18 \\
\hline Protection & -.03 & -.07 & -.01 & -.17 & -.01 & -.03 & -.09 & -.04 & .00 \\
\hline Discipline & .12 & .20 & .24 & .11 & -.16 & .04 & -.25 & .12 & .19 \\
\hline Play & .07 & .04 & .10 & -.07 & -.08 & .06 & -.15 & -.01 & -.08 \\
\hline Teaching & .20 & .19 & .16 & .09 & -.18 & .24 & -.28 & .22 & .27 \\
\hline Instrumental Care & .13 & .09 & $.31 *$ & .00 & -.05 & .02 & -.12 & .07 & .22 \\
\hline
\end{tabular}

Note. ${ }^{*} \mathrm{p}<.05$

\section{Discussion}

Parenting self-efficacy beliefs are well-established in the available literature as a primary correlate of parenting behaviors likely to produce child-rearing environments that are conducive to maximizing children's development. The primary purpose of this study was to extend parenting self-efficacy research into a logical new direction by examining possible associations between parents' self-efficacy beliefs and actual child outcomes. More specifically, this study entailed an exploration of parenting self-efficacy beliefs as predictors of parenting competence, toddlers' overt behavior in a laboratory setting, and toddlers' performance on the Mental Scale (MDI) of the Bayley Scales of Infant Development (BSID-II).

Counter to the first hypothesis, a significant relationship was not observed between mothers' parenting self-efficacy beliefs (measured at both the domain-specific and domaingeneral levels) and the Quality of Assistance and Supportive Presence variables coded based on 
mothers' behavior during the Crowell Procedure. Perhaps stronger relationships between mothers' self-efficacy beliefs and the quality of parenting behaviors would have been detected if a more microanalytic approach to coding mothers' interactive behaviors had been adopted. For example, instead of coding variables such as "encouraging and supporting the child's efforts," which require the rater to decide if the "mother generally responds to the child's discrete actions and efforts to solve the task by showing strong positive affect or some verbal praise or reinforcement," more highly specified behaviors such as positive or negative contingent verbalizations, changes in tone of voice, or physical gestures could have actually been counted.

The means were very high on the two composite assessments of parenting competence. Mothers are undoubtedly more inclined to engage in appropriately stimulating and nurturing behavior when there are few distractions, time is limited, and they are aware of being videotaped than they would be in the home. The mothers were informed that the focus of the study was on individual differences in toddler behavior as well as parenting strategies used during this difficult time in parenting, rendering an element of exaggerated, possibly somewhat artificial, performance likely. Approximately $50 \%$ of the mothers originally contacted consented to participation; therefore it is also very probable that this particular group of participants was more homogeneous in terms of their levels of personal investment in parenting and interest in their children's development than would be evident in the general population.

The Crowell Procedure did not provide an effective means for tapping into the quality of parenting behavior under stressful circumstances as most of the toddlers seemed to enjoy the sequence of activities. Further, conversations with the mothers after testing generally suggested that they appreciated the opportunity to spend some one-on-one time with their toddlers. As indicated previously, the effects of self-efficacy on overt behavior tend to be most salient under stressful circumstances. Perhaps a relationship between self-efficacy beliefs and parenting competence would have emerged if the mother-toddler dyads were observed when the children were tired or under-stimulated and more inclined to exhibit oppositional behavior that would 
have presented a greater challenge to mothers' attempts to keep their children focused and on task.

Many of the parenting behaviors that are likely to be differentially impacted by parents' feelings of efficacy in the role are perhaps difficult to measure based on a relatively brief and structured excerpt of dyadic behavior in a laboratory setting, such as in the Crowell Procedure. Further research on the relationship between parenting self-efficacy and parenting competence under more naturalistic conditions and involving the sampling of behavior over a more extended time frame seems merited before definitive conclusions pertaining to the relationship between parenting self-efficacy and parenting competence among mothers of toddlers can be made. The second hypothesis was not supported as neither domain-specific nor domain-general parenting self-efficacy beliefs were found to predict the toddler behaviors coded during the Crowell Procedure (Enthusiasm, Compliance, Affection towards mother, Persistence, Avoidance of mother, Negativity, and Experience of the session). The lack of significant relationships observed between parental self-efficacy beliefs and the Crowell Procedure toddler behaviors may again have been a reflection of the limits imposed by the testing situation. The laboratory context, complete with interesting toys and mothers' generally undivided attention, may not have been conducive to evoking toddlers' typical at-home behaviors, which are perhaps more likely to have been shaped by their mothers' self-efficacy beliefs. A number of mothers expressed surprise with how cooperative their toddlers were. All of the Crowell Procedure behaviors were moderately to highly inter-correlated and they were all significantly correlated with the toddlers' MDI scores on the Bayley, suggesting that the toddlers generally displayed qualitatively uniform behavior throughout the session. Toddlers in good spirits tended to be affectionate, cooperative, enthusiastic, etc., exhibiting positive behavior for the duration of the Crowell Procedure; whereas toddlers who were more negativistic tended to be so during the entire observation period. Similarly, toddlers who were generally rested and in a positive mood were probably more able to perform optimally on the Bayley Scales. This finding of seemingly non-orthogonal child behaviors is consistent with previously published work employing the Crowell Procedure 
(Crowell \& Feldman, 1988). However, the tendency toward a halo effect may not have been evidenced with observations of children and mothers under more naturalistic, less novel circumstances. For example, Teti and Gelfand's (1991) study of the relationship between maternal self-efficacy beliefs and behavioral competence involved assessment of parenting behavior based on three in-home observations that took place on different days over a 1-month period. Such an approach may be necessary to minimize halo effects likely to occur with testing in an unfamiliar, yet interesting, environment on one occasion.

The majority of the associations among the maternal self-report measures (self-efficacy beliefs, perceptions of difficult child temperament, parenting satisfaction, and stress associated with the parenting role) were significantly inter-correlated as well. Mothers who felt positive about themselves as parents also generally tended to indicate positive perceptions of the parenting experience and of their toddlers.

Significant moderate, positive relationships were observed in this study between parenting competence (Quality of Assistance and Supportive Presence) and toddlers' MDI scores. This finding is consistent with previous research linking various indicators of parenting competence with toddlers' cognitive performance (Bornstein \& Tamis-LeMonda, 1989; McPhee et al., 1984). Both indexes of mothers' behavioral competence were positively associated with the adaptive Crowell Procedure behaviors (Enthusiasm, Compliance, Affection toward mother, Persistence, and Experience of the session) and were negatively associated with undesirable behaviors coded during the Crowell Procedure (Avoidance of mother and Negativity). The link between parenting quality and child behaviors is well-established in the existing literature (Crowell \& Feldman, 1988; Strand \& Wahler, 1996). A strong correlation was detected between the Quality of Assistance and Supportive Presence variables and this result is also similar to what other researchers have found using the Crowell Procedure (Crowell \& Feldman, 1988). Strong associations between child and mother variables and between the indexes of maternal competence could also simply be a reflection of the halo effect discussed previously. Either all of the testing went well with the toddlers generally interested and cooperative and the mothers 
responding appropriately across all behavioral dimensions or the toddlers were irritable and generally difficult. Mothers who were challenged by child difficulty tended to respond appropriately to their toddlers' negative behavior; however, the opportunity to interact as positively as in the former scenario with more agreeable toddlers was not afforded this small minority of mothers.

Bornstein and Tamis-LeMonda (1989) have suggested that various parental factors such as responsiveness may instill children with feelings of self-efficacy, which in turn may foster their desire to acquire information and bolster their performances on cognitive tasks. Maternal responsiveness or sensitivity may provide essential mechanisms for the transmission of high parenting self-efficacy beliefs into parental behavioral competence in addition to promoting achievement enhancing efficacious feelings in children. However, multidimensional constructs, such as sensitivity or responsiveness, are difficult to define in terms of specific behaviors, which are most likely to be influenced by task-related parenting self-efficacy beliefs. Most of the available research designed to examine the relationship between parenting self-efficacy and parenting competence has tended to focus on global indexes of parenting quality and the extent to which highly efficacious parents do actually excel in more specified areas remains largely unexamined, particularly with mothers of toddlers. What seems to be needed is more empirical work that is designed to examine how self-efficacy beliefs influence overt parent and child behaviors through their link to more complex parental factors such as responsiveness, sensitivity, empathy, the capacity to emotionally connect to others, interest in parenting, a sense of responsibility associated with the role, long-range parenting goals or aspirations for one's child, interest in parenting, etc. If subsequent studies include parenting self-efficacy beliefs, several of these more complex internal-type variables, and discrete measure of parenting competence and child outcomes, a more comprehensive, explanatory model is likely to emerge.

Without a comprehensive understanding of how self-efficacy beliefs actually operate, the meaningfulness of the relationships between these parental cognitions and overt assessments of parenting behaviors and child outcomes described in the literature remains somewhat limited. 
As Coleman and Karraker point out (1998), possible means of influence may be identified by drawing on the work of Bandura and his predecessors. First, Coleman and Karraker (1998) note that belief in one's ability to parent effectively is likely to influence the level of stress and/or depression experienced in demanding parenting situations. An expansive literature supports the association between feelings of lacking control over stress and elevated subjective distress involving anxiety and negative physiological reactions (Bandura, Cioffi, Taylor, \& Brouillard, 1988; Bandura, Taylor, Williams, Mefford, \& Barchas, 1985). Parental stress and depression have frequently been found to be associated with negative effects on parenting including child abuse and neglect (Halpern, 1993; Mrazek, 1993) and compromised child outcomes (Donovan \& Leavitt, 1989).

A second avenue of influence discussed by Coleman and Karraker (1998) to explain how self-efficacy beliefs are also likely to relate to parenting behavior involves motivational processes. Self-efficacy beliefs have been shown to have a direct effect on the setting of taskrelated goals (Schunk, 1990). Efficacious individuals tend to establish high and specific performance goals, while those possessing low self-efficacy beliefs are more inclined to shy away from formulating ambitious, specific behavioral goals (Bouffard-Bouchard, 1990; Locke, Frederick, Lee, \& Bobko, 1984). People with low self-efficacy also tend to give up quickly when problems arise (Bandura, 1989). As a result, a mother with low self-efficacy, lacking wellformulated parenting goals might, for example, be expected not to follow through with consequences for child misbehavior in response to a significant level of child pleading. There is also evidence that self-perceptions of efficacy are likely to be related to the actual motivation to actually engage in challenging tasks (Sexton \& Tuckman, 1991). Coleman and Karraker note that parents lacking in self-efficacy are likely to avoid effortful disciplinary techniques, such as induction, opting instead to control behavior through less challenging means such as yelling or spanking.

A third means through which self-efficacy beliefs may conceivably influence parenting behavior discussed by Coleman and Karraker (1998) is through the construction of cognitive 
appraisals pertaining to the possibility of future success or failure. High self-efficacy has been associated with visualization of success scenarios, which provide an effective model for actual future problematic situations (Bandura, 1989). Conversely, individuals with low self-efficacy tend to imagine future failure in addition to being inclined to avoid effortful cognitive activity. Fears, typically focusing on one's perceived limitations, are likely to divert attention away from the actual task behavior and compromise parenting quality in the process.

In addition to the affective, motivational, and cognitive means through which self-efficacy beliefs may potentially impact parenting behavior, effectance beliefs can also directly influence parenting behavior through the predisposition to cope with stressors in particular ways (Coleman \& Karraker, 1998). High self-efficacy has been associated with a preference for problem-focused coping (management of the event); whereas low self-efficacy is usually associated with emotionfocused coping (regulation of emotions associated with the event). There is evidence suggesting that greater reliance on emotion-focused coping may be associated with occupational burnout (Aldwin \& Reverson, 1987), implying it is a less effective coping strategy. Perhaps parents with compromised self-efficacy are more likely to rely on emotion-focused coping, and are therefore more prone to experiencing feelings of being burned out with the responsibilities and work associated with parenting.

The third hypothesis predicted that parenting self-efficacy beliefs would serve to unify various dimensions of parenting through their strength as a mediator between distinct maternal factors (e. g., experience with children, mothers' attachment to their own mothers) and difficult child temperament, and objective (behavioral competency) and subjective (stress and satisfaction associated with the parental role) experiences associated with parenting. Partial support for this hypothesis was obtained based on evidence of mediation observed between child temperament and mothers' reports of parenting stress and satisfaction with parenting using the domain-specific measure.

Mothers' attachment to their own mothers and their reported levels of experience with children other than their own were not found to be very strongly related to either measure of 
parenting self-efficacy, precluding mediation. Perhaps an attachment measure that focuses more on retrospective reports of the quality of mothers' relationships with their own mothers, as opposed to measuring the quality of mothers' current relationships with their mothers would have yielded more predictive power. Moreover, the quality of mothers' relationships with their own mothers may loose strength as a predictor of parenting self-efficacy beliefs as the number of years women have lived independently from their parents increases. With a mean maternal age of nearly 32 years, the mothers included in this study were generally mature women with over a decade of experiences away from their parents. Actual relationships with their own children, involving successes and failures with the tasks of parenting and a host of other factors may have produced more salient informational sources of their efficacy beliefs. The experience variable was only composed of one item, and perhaps a more sophisticated approach to measuring mothers' experiences with children other than their own that tapped into specific types of experiences (e.g., helping to raise siblings, in an employment context, or with family members' children) may have resulted in more promising results.

The inverse relationship observed between mothers' age and scores on the domaingeneral self-efficacy measure necessitating use of the variable as a covariate was counterintuitive in that efficacy beliefs would be expected to increase with life experience. One possible explanation for the association is that older women may have postponed childrearing based on lower feelings of competence related to the care of children.

Both mothers' attachment to their own mothers and maternal experience with children other than their own represent factors that are perhaps more distally related to the everyday experience of raising children; whereas a child's temperament has direct implications on the actual day to day practice of parenting. Perhaps parenting self-efficacy beliefs only exert a mediational role between more immediate aspects of the parenting context and actual parenting behavior. Subsequent research designed to examine the mediational role of self-efficacy should explore the possibility that other proximal context variables such as child physical or mental illness, stressful life events (e.g., frequent relocation, unemployment, divorce, economic hard 
ship, etc.), or the difficult child behavior that characterizes different points in development, exert an impact on parenting outcomes through their effects on parents' self-efficacy beliefs.

Research pertaining to self-efficacy tends to be restricted primarily to either the domain or the general levels of analysis. As a result, very little is known about how assessments of selfefficacy beliefs based on discrepant conceptualizations may be related or may differentially impact behavior. The results of this study revealed significant moderate correlations between scores on the domain-general measure and the two measures of domain-specific self-efficacy beliefs. A few other isolated studies have found moderate correlations between general and more task-oriented self-efficacy measures, implying that generalized self-efficacy indexes may operate as an informational source used to estimate domain-specific self-efficacy or conversely that taskspecific beliefs converge to produce more generalized efficacy beliefs (Watt \& Martin, 1994; Woodruff \& Cashman, 1993). In an unpublished report on mothers of elementary school-age children by Coleman and Karraker (1997), domain-general parenting self-efficacy beliefs and general self-efficacy beliefs were found to operate as significant predictors of parenting selfefficacy beliefs derived from a task level of analysis. Coleman and Karraker note that an interesting question for subsequent work in this area pertains to the degree to which self-efficacy beliefs assessed at more global levels of analysis facilitate or deter the acquisition of parenting self-efficacy beliefs associated with particular tasks as children enter new phases of development. For example, if a mother feels generally competent as a parent when her child is an infant, will it be easier for her to feel competent establishing rules for her child when he or she enters the preschool period?

As described earlier, Bandura (1989) has suggested that domain-specific measures of self-efficacy, when compared to more global assessments, are likely to be more precise in terms of predicting actual behavior. In the present study, neither domain-specific nor domain-general self-efficacy beliefs were found to be related to the two measures of parenting competence nor any of the toddler outcome measures. However, evidence for mediation between child 
temperament and parents' subjective impressions of the parenting experience was only revealed with the domain-specific measure.

Some support for the superior predictive validity of the domain-specific measure over a well-established domain-general measure with data generated from a relatively small sample and resulting low statistical power is very promising for future research efforts adopting a similar measurement strategy. Although extensive psychometric analysis of the SEPTI-TS was not possible given the small sample size, preliminary internal consistency reliability evidence and correlations with other measures were promising. With further refinement, it seems very likely that the SEPTI-TS, which is based on a conceptualization of the construct in a manner that is consistent with the Bandurian tradition and taps into parents' efficacy beliefs relative to a wide range of parenting behaviors, is likely to provide a useful instrument for further work in this area.

An obvious limitation of this study was the use of a relatively homogeneous sample, precluding generalizabilty to mothers with socio-demographic backgrounds discrepant from the study participants. The majority of the mothers sampled were married, white, middle-class, and relatively well-educated, residents of a rural, politically conservative community. Cultural influences on the role of parenting self-efficacy have been revealed in recent studies. For example, Elder, Eccles, Ardelt, \& Lord's (1995) work demonstrated that among economically stressed African Americans and European Americans there was a relationship between low income and parental self-efficacy; however the association between the two variables was mediated by depression only among the European Americans. Dumka et al. (1996) conducted a study comparing two very discrepant groups of mothers, differing in terms of income, education, cultural background (Mexicans having recently immigrated to the U.S. and U.S. residents of a large university town), and dominant language. Interestingly, this group of researchers found an inverse relationship between self-efficacy and inconsistent discipline among the Anglos, but not among the Mexican immigrants. Further, only with the Anglo group did the use of active coping strategies in problem-solving correlate with self-efficacy and only among the Mexican immigrants did the use of a particular emotion-focused coping technique (positive 
reinterpretation or thinking back on the stressful event) relate to high self-efficacy. Unfortunately, sensitivity to racial, ethnic, SES, gender, national, and cultural diversity has not been a primary concern in most topical areas of developmental psychology (Lerner, 1995). However, the few findings to date clearly suggest contextually driven differences in the effects of self-efficacy, thereby highlighting the importance of considering demographic factors as the research on parenting self-efficacy develops. Ultimately, understanding the range of effects of individual differences in parenting self-efficacy across a multitude of environmental contexts is the only valid approach for arriving at meaningful indexes of interindividual generalizability.

The lack of significant associations observed between self-efficacy beliefs and both parenting behavior and child outcomes could very well have been a product of the limitations imposed by the methodology employed. However, it is also certainly plausible that self-efficacy beliefs are simply not associated with overt parent and child behavior within this subgroup of mother-child dyads. Previous research revealing an association between maternal self-efficacy beliefs and the quality of parenting has tended to be conducted with demographically diverse samples (e.g., Gross, Conrad, Fogg, \& Wothke, 1994) or samples that include a mix of both mothers who are both clinically depressed and non-depressed (e.g., Teti \& Gelfand, 1991). Typically, analyses are not conducted based on separate subgroups due to restrictive sample sizes. Testing for associations between self-efficacy beliefs and parent and child outcomes with a heterogeneous sample obviously has the advantage of maximized variance. There was very little behavioral variability in the present study, with the exception of that added by a few irritable toddlers. Further, the variability detected relative to self-efficacy beliefs was clustered around the high ends of the scales. With a segment of the population that is very homogeneous with respect to their perceptions of competence as well as their actual competence, the hypothesized relations may not exist.

The current study provides some interesting data pertaining to parenting self-efficacy beliefs among mothers of toddlers at one point in time. However, research pertaining to the relative stability (or absence thereof) characteristic of parenting self-efficacy across a range of 
child ages is also very much needed as this literature base matures. A few longitudinal studies restricted to pregnancy and the first few years of parenting have been conducted. For example, Williams et al. (1987) found that confidence in one's future parenting abilities operated as a strong predictor of maternal competence from the 8th month of pregnancy through two years postpartum. In fact, maternal perceptions of competence specific to the parenting domain were found to be more effective predictors of maternal adjustment than prior experience with infants and a global self-esteem index. Schneewind (1995) found perceptions of parenting competence were stable between 3 and 9 months following the birth of a child among both mothers and fathers. Likewise, Gross and her colleagues (1994) reported moderately high levels of consistency in self-efficacy beliefs in mothers from the time their toddlers were 12 to 36 months of age. Additional longitudinal research is needed to examine the explanatory power of parental self-efficacy beliefs for understanding differences in parenting quality across various child ages and to identify continuities and discontinuities of perceived competence over the course of developmental changes in children. Exploration of possible normative changes in parenting selfefficacy over a wide range of child ages remains virtually unexamined.

The present study, like most of the existing parenting self-efficacy research, investigated the construct concurrently with various indexes of parenting quality, maternal variables, and child characteristics, precluding the confirmation of directional effects. Subsequent prospective research efforts should help decipher the temporal relations between self-efficacy beliefs and various dimensions of parenting and child behavior. Nevertheless it is important to remain cognizant of the possibility that complex, multidirectional relationships among self-efficacy and other variables relevant to parenting are operative in the development of parenting competence and children's development (Coleman \& Karraker, 1998). For instance, the possibility that perceptions of difficult temperament attenuate self-efficacy beliefs is as equally logical as the reverse, and the expression of each variable is surely influenced by multiple other factors and processes. 
Data generated in the context of the current study and correlational data generated from previous work have highlighted the importance of parental self-efficacy beliefs as a correlate of subjective responses to the caregiving role. Subsequent intervention-based research efforts should be directed toward clarification of whether the previously detected relationships are causal in nature. Direct manipulation of parental self-efficacy beliefs in the context of an intervention treatment program is, therefore, an important direction for further work. The existing foundation of strong correlational data provides a substantial impetus for higher constraint research. A recent study progressing in this important direction was conducted by Gross, Fogg, and Tucker (1995) with the parents of 46 two-year-olds. These investigators found that attendance in a 10-week parent-training intervention program focusing on teaching parents how to effectively interact with their toddlers resulted in significant increases in parenting selfefficacy, decreases in parenting stress, and substantial improvements in the quality of parenttoddler interactions. The participants were provided with information pertaining to how to play with their children, how to encourage learning in their children, effective use of praise and rewards, limit setting strategies, and how to manage misbehavior. Participants watched and discussed videotaped vignettes of parent and child models engaged in typical family interactions, and the format of the program was designed to provide experiences conducive to the enhancement of self-efficacy beliefs. More specifically, parents were able to receive self-efficacy information based on mastery experiences derived from weekly homework assignments, vicarious learning through the use of the videos, and verbal persuasion via mutual support and reinforcement in the group setting.

The emergence of self-efficacy beliefs as a mediator of the effects of child temperament on stress and satisfaction associated with the parenting role is exciting from a practical as well as from a scientific perspective. Self-efficacy is a variable that merits more attention in theoretical models of parenting and child development as it appears to act as a guiding force behind much of the parenting experience. Moreover, identification of a possible correlate of parenting 
competence and children's behavioral development that may conceivably be altered ushers in hope of optimizing children's early experiences.

Parenting self-efficacy is a relatively new research area possessing great promise for resolving many ambiguities related to individual differences in adapting to parenting. However, several avenues for further study of parenting self-efficacy remain virtually unexamined. For example, difficult child temperament was examined generally in this study, but perhaps there are more specific dimensions of temperament such as activity level, shyness, emotional reactivity etc. that may be more closely associated with individual differences in parental self-efficacy in mothers of toddlers. Are there certain parental personality characteristics or environmental situations that tend to predispose individuals to high or low parenting self-efficacy? How resistant to change are parental self-efficacy beliefs in the face of non-normative events such as the presence of a lengthy physical or mental illness or divorce? Do mothers tend to have higher self-efficacy beliefs than fathers, because they tend to have more direct care experiences and their roles are currently perhaps more well-defined than those of fathers? Do children tend to form closer emotional bonds with the more efficacious of their parents? Do mothers' and fathers' self-efficacy beliefs tend to differ depending on the referent tasks? How does parenting selfefficacy influence other aspects of parents' lives? For example, do parents with low parental selfefficacy experience difficulty concentrating at work? Are social lives or marital intimacy compromised with low parenting self-efficacy? Are there life-enhancing benefits that extend beyond parenting for those fortunate enough to experience high parental self-efficacy beliefs? What are the mental health implications for parents who raise their children, without ever having achieved a sense of personal competence in the role?

Research findings cited earlier have consistently revealed that individuals possessing low and high estimations of perceived self-efficacy display distinct affective, motivational, and cognitive reactions to widely varying task situations in addition to exhibiting discrepant behavioral responses. People with a high sense of perceived efficacy relative to a particular behavioral domain confidently trust their own abilities in the face of environmental demands, are 
inclined to approach problems as challenges, experience low levels of negative emotional arousal when engaged in difficult tasks, persevere when facing adversity, and are inclined to set high goals for themselves (Jerusalem \& Mittag, 1995). In contrast, when individuals possess low selfefficacy, they often experience self-doubt and anxiety during adversity, assume more responsibility for failure than success, appraise demanding situations as personally threatening, avoid challenge, and cope ineffectively with problems (Jerusalem \& Mittag, 1995).

Efficacious parents experience a sense of personal empowerment in parenting that seems to optimize their capacities to successfully manage and perform the multifaceted tasks of the parental role and fosters enjoyment in the process. An efficacious parental outlook should facilitate intrinsic interest in parental activities and deep engrossment in the parenting process, rendering it a deeply meaningful experience (Bandura, 1995). On the opposite end of the spectrum, inefficacious parents tend to feel overwhelmed by their parental responsibilities, often actually becoming immobilized by the emotional and physical tasks of parenthood. Although the results of this investigation did not reveal a significant relationship between maternal selfefficacy beliefs and child outcomes, associations between parenting self-efficacy beliefs and the quality of children's interactive behavior and their developmental status have been demonstrated in a few previous investigations employing larger, more heterogeneous samples (Donovan \& Leavitt, 1985; Elder et al., 1995; Swick \& Hassell, 1990). The direct and indirect ramifications of deficiencies in parental perceptions of competency for child social, affective, and cognitive development remain largely unexamined and represent fertile ground for further investigative efforts with socio-demographically diverse parents. 


\section{References}

Abidin, R. R. (1990). Parenting Stress Index manual (4th ed.). Charlottesville, VA: Pediatric Psychology Press.

Aldwin, C. M., \& Revenson, T. A. (1987). Does coping help? A reexamination of the relation between coping and mental health. Journal of Personality and Social Psychology, 53, $337-348$.

Ainsworth, M. D. S., Blehar, M. C., Waters, E., \& Wall, S. (1978). Patterns of attachment: A psychological study of the strange situation. Hillsdale, NJ: Lawrence Erlbaum.

Andresen, P. A., \& Telleen, S. L. (1992). The relationship between social support and maternal behaviors and attitudes: A meta-analytic review. American Journal of Community Psychology, 20, 753-774.

Armsden, G. C., \& Greenberg, M. T. (1987). The Inventory of Parent and Peer Attachment: Individual differences and their relationships to psychological well-being in adolescence. Journal of Youth and Adolescence, 16, 427-454.

Bakermans-Kranenburg, M. J., \& van IJzensoorn, M. H. A psychometric study of the adult attachment interview: Reliability and discriminant validity. Developmental Psychology, 29, 870879.

Ballenski, C. B., \& Cook, A. S. (1982). Mothers' perceptions of their competence in managing selected parenting tasks. Family Relations, 31, 489-494.

Bandura, A. (1977). Self-efficacy: Toward a unifying theory of behavioral change. Psychological Review, 84, 191-215.

Bandura, A. (1982). Self-efficacy in human agency. American Psychologist, 37, 122-147.

Bandura, A. (1989). Regulation of cognitive processes through perceived self-efficacy. Developmental Psychology, 25, 729-735.

Bandura, A. (1995). Exercise of personal and collective efficacy in changing societies. In A. Bandura (Ed.), Self-efficacy in changing societies, (pp. 1-45). New York: Cambridge University Press. 
Bandura, A., Babaranelli, C., Caprara, G. V., \& Pastorelli, C. (1996). Multifaceted impact of self-efficacy on academic functioning. Child Development, 67, 1206-1222.

Bandura, A., Cioffi, C., Taylor, C.B., \& Brouillard, M.E.( 1988). Perceived self-efficacy in coping with stressors and opioid activation. Journal of Personality and Social Psychology, 55. 479-488.

Bandura, A., Taylor, C.B, Williams, S. L., Mefford, I.N., \& Barchas, J.D. (1985). Catacholamine secretion as a function of perceived copping self-efficacy. Journal of Consulting and Clinical Psychology, 53, 406-414.

Baron, R.M., \& Kenny, D. A. (1986). The moderator-mediator variable distinction in social psychological research: Conceptual, strategic, and statistical considerations. Journal of Personality and Social Psychology, 51, 1173-1182.

Bates, J. E., Freeland, C. A., \& Lounsbury, M. L. (1979). Measurement of infant difficultness. Child Development, 50, 784-803.

Bayley, N. (1993). Manual for the Bayley Scales of Infant Development. New York: The Psychological Corporation.

Beck, K. H., \& Lund, A. K. (1981). The effects of health threat seriousness and personal efficacy upon intentions and behavior. Journal of Applied Social Psychology, 11, 401-415.

Belsky, J. (1981). Early human experience: A family perspective. Developmental Psychology, 17, 3-23.

Belsky, J. (1984). The determinants of parenting: A process model. Child Development, 55, 83-96.

Blumberg, N. L. (1980). Effects of neonatal risk, maternal attitude, and cognitive style on early postpartum adjustment. Journal of Abnormal Psychology, 89, 139-150.

Bohlin, G., \& Hagekull, B. (1987). Good mothering: Maternal attitudes and mother-infant interaction. Infant Mental Health Journal, 8, 352-363.

Bouffard-Bouchard, T. (1990). Influence of self-efficacy on a cognitive task. The Journal of Social Psychology, 130, 353-363. 
Brazelton, T. B. (1992). Touchpoints. Reading MA: Addison-Wesley.

Bugental, D. B. (1991). Affective and cognitive processes within threat-oriented family systems. In I. E. Sigel, A. V. McGillicuddy-DeLisi, \& J.J. Goodnow (Eds.), Parental belief systems: The consequences for children. Hillsdale, NJ: Lawrence Erlbaum.

Bugental, D. B., Blue, J., \& Cruzcosa, M. (1989). Perceived control over caregiving outcomes: Implications for child abuse. Developmental Psychology, 25, 532-539.

Bus, A. G., \& van IJzendoorn, M. H. (1988). Mother-child interactions, attachment, and emergent literacy: A cross-sectional study. Child Development, 59, 1262-1272.

Buss, D. M. (1981). Predicting parent-child interactions from children's activity level. Developmental Psychology,17, 59-65.

Cohen, S., \& Bromet, E. (1992). Maternal predictors of behavioral disturbance in preschool children: A research note. Journal of Child Psychology and Psychiatry, 33, 941-946.

Cohen, J., \& Cohen, P. (1983). Applied regression/correlation analysis for the behavioral sciences. Hillsdale, NJ: Erlbaum.

Coleman, P. K., \& Karraker, K. H. (Unpublished manuscript) Parenting self-efficacy among mothers of school-age children: Conceptualization, measurement, and predictors. Submitted to the Family Relations.

Coleman, P. K., \& Karraker, K. H. (1998). Self-efficacy and parenting quality: Findings and future applications. Developmental Review, 18, 47-85.

Conrad, B., Gross, D., Fogg, L., \& Ruchala, P. (1992). Maternal confidence, knowledge, and quality of mother-toddler interactions: A preliminary study. Infant Mental Health Journal, $13,353-362$.

Cox, A., Puckering, C., Pound, A., \& Mills, M. (1987). The impact of maternal depression in young children. Journal of Child Psychology and Psychiatry, 28, 917-928.

Cronenwett, L. (1985). Network structure, social support, and psychological outcomes of pregnancy. Nursing Research, 34, 93-99. 
Crowell, J. A., \& Feldman, S. S. (1988). Mothers' internal models of relationships and children's behavioral and developmental status. Child development, 59, 1273-1285.

Cutrona, C. \& Troutman, B. (1986). Social support, infant temperament, and parenting self-efficacy: A mediational model of postpartum depression. Child Development, 57, 15071518.

Deutsch, F. M., Ruble, D. N., Fleming, A., Brooks-Gunn, J., \& Stangor, G. S. (1988). Information seeking and maternal self-definition during the transition to motherhood. Journal of Personality and Social Psychology, 55, 420-431.

Donovan, W. L., \& Leavitt, L. A. (1985). Simulating conditions of learned helplessness: The Effects of interventions and attributions. Child Development, 56, 594-603.

Donovan, W., Leavitt, L. A., \& Walsh, R. O. (1990). Maternal self-efficacy: Illusory control and its effect on susceptibility to learned helplessness. Child Development, 61, 16381647.

Dumka, L., E., Stoerzinger, H. D., Jackson, K. M., \& Roosa, M. W. (1996). Examination of the cross-cultural and cross-language equivalence of the Parenting Self-Agency Measure. Family Relations, 45, 216-222.

Dunham, P., \& Dunham, F. (1992). Lexical development during middle infancy: A mutually driven infant-caregiver process. Developmental Psychology, 28, 414-420.

Egeland, B., \& Farber, E. (1984). Infant-mother attachment: Factors related to its development and changes over time. Child Development, 55, 753-771.

Earley, P. C., \& Lituchy, T. R. (1991). Delineating goal and efficacy effects: A test of three models. Journal of Applied Psychology, 76, 81-98.

Edwards, C. P. (1995). Parenting toddlers. In M. H. Bornstein (Ed.), $\underline{\text { Handbook of }}$ parenting: Volume 1 Children and parenting (pp. 41-63). Mahwah, NJ: Erlbaum.

Elder, G. H. (1995). Life trajectories in changing societies. In A. Bandura (Ed.), Selfefficacy in changing societies, (pp. 46-68). New York: Cambridge University Press. 
Elder, G. H., Eccles, J. S., Ardelt, M., \& Lord, S. (1995). Inner city parents under economic pressure: Perspectives on the strategies of parenting. Journal of Marriage and the Family, 57, 771-784.

Emde, R. N. (1989). The infant's relationship experience: Developmental and clinical aspects. In A. J. Sameroff \& R. N. Emde (Eds.), Relationship disturbances in early childhood (pp. 33-51). New York: Basic Books.

Field, T. M. (1984). Early interaction between infants and their postpartum depressed mothers. Infant Behavior and Development, 7, 527-532.

Field, T. M., Healy, B., Goldstein, S., Perry, S., Bendell, D., Schanberg, S., Zimmerman, E. A., \& Kuhn, C. (1988). Infants of depressed mothers show "depressed" behavior even with nondepressed adults. Child Development, 59, 1569-1579.

Fleiss, J.C. (1981) Statistical methods for rates and Proportions. New York: Wiley.

Gelfand, D. M., \& Teti, D. M. (1990). The effects of maternal depression on children. Clinical Psychology Review,10, 329-353.

Glass, J. (1983). Pre-birth attitudes and adjustment to parenthood: When 'preparing for the worst' helps. Family Relations, 32, 377-386.

Goodnow, J. J. (1985). Change and variation in ideas about childhood and parenting. In I. E. Sigel (Ed.), Parental belief systems: The psychological consequences for children. Hillsdale, NJ: Lawrence Erlbaum.

Goodnow, J. J., \& Collins, W. A. (1990). Development according to parents: The nature, sources, and consequences of parents' ideas. Hillsdale, NJ: Lawrence Erlbaum.

Gross, D., Conrad, B., Fogg, L., \& Wothke, W. (1994). A Longitudinal model of maternal self-efficacy, depression, and difficult temperament during toddlerhood. Research in Nursing and Health, 17, 207-215.

Gross, D., Fogg, L., \& Tucker, S. (1995). The efficacy of parent training for promoting positive parent-toddler relationships. Research in Nursing and Health, 18, 489-499. 
Grusec, J. E., Hastings, P., \& Mammone, N. (1994). Parenting cognitions and relationship schemas. In J. G. Smetana (Ed.), Beliefs about parenting: Origins and developmental implications (pp. 5-19). San Francisco: Jossey-Bass.

Hagekull, B., \& Bohlin, G. (1990). Early infant temperament and maternal expectations related to maternal adaptation. International Journal of Behavioral Development, 13, 199-214.

Halpern, R. (1993). Poverty and infant development In C. H. Zeanah (Ed.), Handbook of infant mental health, (pp. 73-86). New York, Guilford Press.

Harter, S. (1978). Effectance motivation reconsidered: Toward a developmental model. Human Development, 21, 34-64.

Hinde, R. A., \& Stevenson-Hinde, J. (1987). Interpersonal relationships and child development. Developmental Review, 7, 1-21.

Huttenlocher, J., Haight, W., Bryk, A., Seltzer, M., \& Lyons, T. (1991). Early vocabulary growth: Relation to language input and gender. Developmental Psychology, 27, 236-248.

Izard, C. E. (1977). Human emotions. New York: Plenum Press.

Johnston, C., \& Mash, E. J. (1989). A measure of parenting satisfaction and efficacy. Journal of Clinical Child Psychology, 18, 167-175.

Kochanska, G. (1990). Maternal beliefs as long term predictors of mother-child interaction and report. Child Development, 61, 1934-1943.

Lachman. M. E., \& Leff, R. (1989). Perceived control and intellectual functioning in the elderly: A 5-year longitudinal study. Developmental Psychology, 25, 722-728.

Lamb, M. E., Thompson, R. A., Gardner, W., \& Charnov, E. L. (1985). Infant-mother attachment: The origins and developmental significance of individual differences in strange situation behavior. Hillsdale, NJ: Lawrence Erlbaum Associates.

Lerner, R. M. (1995). Developing individuals within changing contexts: Implications of developmental contextualism for human development research, policy, and programs, In T. A. Kindermann \& J. Valsiner (Eds.), Development of person-context relations (pp. 13-37). Hillsdale, NJ: Lawrence Erlbaum. 
Locke, E. A., Frederick, E., Lee, C, \& Bobko, P. (1984). Effect of self-efficacy, goals, and task strategies on task performance. Journal of Applied Psychology, 69, 241-251.

Luster, T., \& Mittelstaedt, M. (1993). Adolescent mothers. In T. Luster \& L. Okagaki (Eds.), Parenting: An ecological perspective. Hillsdale, NJ: Lawrence Erlbaum.

Lyons-Ruth, K., Connell, D. B., Zoll, D., \& Stah, J. (1987). Infants at social risk: Relations among infant maltreatment, maternal behavior, and infant attachment behavior, Developmental Psychology, 23, 223-232.

Matas, L., Arend, R. A., \& Sroufe, L. A. (1978). Continuity of adaptation in the second year: The relationship between quality of attachment and later competence. Child development, 49, 547-556.

Maccoby, E. E. (1984). Middle childhood in the context of the family. In W.A. Collins (Ed.), Development during middle childhood: The years from 6 to 12 (pp.184-239). Washington, DC: National Academy.

Maccoby, E. E., \& Martin, J. A. (1983). Socialization in the context of the family. In E. M. Hetherington (Ed.), Handbook of child psychology: Vol. 4. Socialization, personality, and social development. (pp. 1-101). New York: Wiley.

MacPhee, D., Ramey, C. T., \& Yeates, K. O. (1984). Home environment and early cognitive development: Implications for intervention. In A. W. Gottfried (Ed.), Home Environment and Early Cognitive Development. (pp. 343-369).Orlando, FL: Academic Press Inc.

McCall, R. B. (1981). Nature-nurture and two realms of development: A proposed integration with respect to mental development. Child Development,52, 1-12.

Main, M., \& Stadtman, J. (1981). Infant response to rejection of physical contact by the mother. Journal of the American Academy of Child Psychiatry, 20, 292-307.

Mash, E. J., \& Johnston, C. (1983). Parental perceptions of child behavior problems, parenting self-esteem, and mothers' reported stress in younger and older hyperactive and normal children. Journal of Consulting and Clinical Psychology, 51, 86-99. 
Melson, G. F., Ladd, G. W., \& Hsu, H. (1993). Maternal support networks, maternal cognitions, and young children's social and cognitive development. Child Development, 64, 1401-1417.

Mirazek, P. (1993). Maltreatment and infant development. In C. H. Zeanah (Ed.), Handbook of infant mental health (pp. 159-170). New York: Guilford.

Multon, K. D., Brown, S. D., \& Lent, R. W. (1991). Relation of self-efficacy beliefs to academic outcomes: A meta-analytic investigation. Journal of Counseling Psychology, 38, 3038.

Nakagawa, M., Teti, D. M., \& Lamb, M. E. (1992). An ecological study of child-mother attachments among Japanese sojourners in the United States. Developmental Psychology, 28, 584-592.

Pajares, F., \& Miller, M. D. (1995). Mathematics self-efficacy and mathematics performances: The need for specificity of assessment. Journal of Counseling Psychology, 42. 190-198.

Petterson, L., Farmer, J., \& Kashani, J. (1990). Parental injury prevention endeavors: A function of health beliefs? Health Psychology, 9, 177-191.

Pridham, K. F., \& Chang, A. S. (1992). Transition to being the mother of a new infant in the first 3 months: Maternal problem solving and self-appraisals. Journal of Advanced Nursing, 17, 204-216.

Radke-Yarrow, M. (1990). Family environments of depressed and well parents and their children: Issues of research methods. In G. R. Patterson (Ed.), Depression and aggression in family interaction (pp. 169-184). Hillsdale, NJ: Lawrence Erlbaum.

Resnick, J. S., Corley, R., \& Robinson, J. (1997). A longitudinal twin study of intelligence in the second year. Monographs of the Society for Research in Child Development, 62, Series No. 249, No. 1.

Schneewind, K. A. (1995). Impact of family processes on control beliefs. In A. Bandura (Ed.), Self-efficacy in changing societies, (pp. 1-45). New York: Cambridge University Press. 
Schunk, D. H. (1990). Goal-setting and self-efficacy during self-regulated learning. Educational Psychologist, 25, 71-86.

Shelton, S. H. (1990). Developing the construct of general self-efficacy. Psychological Reports, 66, 987-994.

Sherer, M., \& Adams, C. (1983). Construct validity of the Self-Efficacy Scale. Psychological Reports, 53, 899-902.

Sexton, T. L., \& Tuckman, B. W. (1991). Self-beliefs and behavior: The role of selfefficacy and outcome expectation over time. Personality and Individual Differences, 12, 725736.

Slade, A. (1987). A longitudinal study of maternal involvement and symbolic play during the toddler period. Child Development, 58, 367-375.

Smetana, J. G. (1994). Editor's notes. In J. G. Smetana (Ed.), Beliefs about parenting: Origins and developmental implications (pp.1-4). San Francisco: Jossey-Bass.

Spoth, R., \& Conroy, S. (1993). Survey of prevention-relevant beliefs and efforts to enhance parenting skills among rural parents. The Journal of Rural Health, 9, 227-239.

Stafford, L., \& Bayer, C. L. (1993). Interaction between parents and children. Newbury Park CA: Sage Publications.

Stoiber, K. C., \& Houghton, T. G. (1993). The relationships of adolescent mothers' expectations, knowledge, and beliefs to their young children's coping behavior. Infant Mental Health Journal, 14, 61-79.

Strand, P. S., \& Wahler, R. G. (1996). Predicting maladaptive parenting: Role of maternal object relations. Journal of Clinical Child Psychology, 25, 43-51.

Swick, K. J., \& Hassell, T. (1990). Parental efficacy and the development of social competence in young children. Journal of Instructional Psychology, 17, 24-32.

Teti, D. M., \& Gelfand, D. M. (1991). Behavioral competence among mothers of infants in the first year: The mediational role of maternal self-efficacy. Child Development, 62, 918-929. 
Teti, D. M., Gelfand, D. M., Messinger, D. S., \& Isabella, R. (1995). Maternal depression and the quality of early attachment: An examination of infants, preschoolers and their mothers. Developmental Psychology, 31, 364-376.

Tipton, R. M., \& Worthington, E. L. (1984). The measurement of generalized self-efficacy: A study of construct validity. Journal of Personality Assessment, 48, 545-548.

Unger, D. G., \& Wandersman, L. P. (1985). Social support and adolescent mothers: Action research contributions to theory and application. Journal of Social Issues, 41, 29-45.

van den Boom, D. (1984). The influence of temperament and mothering on attachment and exploration: An experimental manipulation of sensitive responsiveness among lower-class mothers and irritable infants. Child Development, 65, 1457-1477.

van IJzendoorn, M. H. (1992). Intergenerational transmission of parenting: A review of studies in nonclinical populations. Developmental Review, 12, 76-99.

Vondra, J., \& Belsky, J. (1993). Developmental origins of parenting: Personality and relationship factors. In T. Luster, \& L. Okagaki (Eds.), Parenting: An ecological perspective. Hillsdale, NJ: Lawrence Erlbaum.

Williams, T. M., Joy, L. A., Travis, L., Gotowiec, A., Blum-Steele, M., Aiken, L. S., Painter, S. L., \& Davidson, S. M. (1987). Transition to motherhood: A longitudinal study. Infant Mental Health Journal, 8, 251-265. .

Wang, A. Y., \& Richarde, R. S. (1988). Global versus task-specific measures of selfefficacy. The Psychological Record, 38, 533-541.

Watt, S. E., \& Martin, P. R. (1994). Effect of general self-efficacy expectancies on performance attributions. Psychological Reports, 75, 951-961.

Wells-Parker, E.., Miller, D. I., \& Topping, S. (1990). Development of control of outcome scales and self-efficacy scales for women in four life roles. Journal of Personality Assessment, 54, 564-575. 
Zeanah, C. H., Boris, N.W., Heller, S. S., Hinshaw-Fuselier, S., Larrieu, J. A., Lewis, M., Palomino, R., Rovaris, M., \& Valliere, J. (1997). Relationship assessment in infant mental health. Infant Mental Health Journal, 18, 182-197. 
Appendix A

Demographic Questionnaire

1. What is your current age?

2. How many children do you have? What are their ages?

3. What is the highest grade in school or year in college that you have completed? What degrees have you earned?

4. What is your current marital status?___ If you are married, is your current marriage your first?

5. Please circle your race below.

$$
\text { Black White Asian Other }
$$

6. Please circle your current employment status.

$$
\text { Unemployed Employed Part-Time Employed Full-Time }
$$

7. What is your annual total household gross income?

8. Please circle the response that best describes the extent of your past experience with children other than your own?

$$
\text { None Very Little Moderate Amount Very Much }
$$

9. What is your child's date of birth?

10. What is your child's current age in months?

11. Please circle your child's gender.

Male Female

12. Please circle your child's current weekly care arrangement

Full-time care (21-40 hrs.) in center daycare

Full-time care (21-40 hrs.) in provider's home

Full-time (21-40) non-maternal care in home

Full-time maternal care

Part-time (20 hours or less) center care

Part-time (20 hours or less) in provider's home

Part-time (20 hours or less) non-maternal care 
13. Please describe your child's daily care arrangement since birth in detail below

14. At what age did your child first walk without help?

15. Has your child begun toilet training? If so, at what age?

16. When did your child speak his/her first meaningful word?

17. Please circle your child's current sleeping arrangement.

Sleeps alone in his/her own bed or crib all night.

Sleeps part of the night alone and part of the night with me

Sleeps in my bed all night

Sleeps part of the night alone and part of the night with a sibling

Sleeps with a sibling all night

18. Does your child use a blanket, pacifier, or other security object?

Yes No

If yes, what is it?

******************************************************************************

19. Please give your current address and telephone number to enable us to contact you if needed during the study.

Address:

Telephone Number: 


\section{Appendix B}

The Self-Efficacy for Parenting Tasks Index - Toddler Scale (SEPTI-TS)

\section{Emotional Availability}

1. Even when I have had an unusually distressing day, I think my child knows I am available to meet his or her emotional needs.

2. I believe that I adequately meet my child's needs to feel secure and accepted.

3. When my child needs me, I am able to easily put aside whatever else I may be doing.

4. I find it difficult to always be available to provide my child with the comfort he/she needs in dealing with the many frustrations and fears that toddlers face each day.

5. Providing physical comfort for my child is easy for me.

6. I am usually willing to stop what I'm doing and cuddle my child when he/she seems to need affection.

7. I am often too preoccupied with my own problems to keep up with my child's changing emotions.

\section{Nurturance/ Valuing/ Empathetic Responsiveness}

8. I am able to sense when my child is starting to become distressed.

9. My toddler knows that I understand when his/her feelings are hurt.

10. I think my child knows by my behavior how much I really adore him/her.

11. My child feels very loved by me.

12. I think I am tolerant and understanding when my child displays negative emotions.

13. I find it very distressing when my child isn't in a good mood.

14. I definitely fulfill my parental duties when it comes to providing emotional support for my child.

15. When my child has a problem, he/she knows I will want to help.

\section{Protection}

16. Providing a safe, hazard-free environment for my child is very difficult for me.

17. I feel comfortable with my ability to react well should an emergency arise in which my child's physical well-being is in danger.

18. When I leave my child in someone else's care, I make sure that the substitute care provider will be capable of protecting my child from harm.

19. I have my home arranged to prevent as many accidents as possible with my toddler. 
20. I am very good about never leaving my child unattended.

21. I always make sure I can see my child in order to make sure he/she does not get hurt.

22. I have difficulty determining what is and is not safe for my child to do.

\section{Discipline/ Limit Setting}

23. Disciplining my child does not seem to be coming as naturally to me as other parts of parenting.

24. I have trouble getting my child to listen to me.

25. Other parents seem to have more success with setting limits for their children than I do with my child.

26. Setting limits for my toddler is relatively easy for me.

27. When my toddler tests the limits that I have set up, I find myself becoming extremely discouraged.

28. Telling my child "no" when safety isn't the issue is hard for me.

29. I allow my child enough freedom to actively explore the environment.

\section{Play}

30. I can always think of something to play with my child.

31. I am a fun playmate for my toddler.

32. I find it hard to loosen up and just play with my child.

33. I am able to get actively involved in playing with my child.

34. Playing is a part of my relationship with my child that I have very little difficulty with.

35. I really need to learn how to just have fun with my child.

36. I think I spend an appropriate amount of time just playing with my child

\section{Teaching}

37. I believe my toddler learns a great deal from my efforts to show him/her things.

38. Assisting my child with learning to talk and understand words is a part of parenting that I leave to others.

39. Sitting down regularly with my child to read or do some other one-on-one activity is not difficult for me.

40. I am probably not that great at teaching my child about the world. 
41. I have some difficulty figuring out the appropriate level of instruction when I'm trying to explain something to my child.

42. Helping my child learn colors, names of objects, etc. is not one of my strongest points.

43. My child learns more from me than anyone else in his/her life.

44. I easily find opportunities to point out things about the world during my daily interactions with my child.

45. Although I would like to help my child learn more about his/her surroundings, this is an area of parenting that I do not feel well-equipped for.

\section{Instrumental Care/ Structure/ Routines}

46. I have been able to establish a daily routine with my toddler that feels comfortable to both of us.

47. I am able to provide my child with a comfortable amount of daily structure.

48. I have been successful in getting my child to eat on a fairly regular schedule.

49. I feel like I have no control over my child's sleep habits.

50. I am not very good at getting my child to stick to a regular daily schedule.

51. Although I have tried to train my child to eat well, my efforts have been met with very little success.

52. I don't seem to be able to establish a regular bed time routine with my child.

53. I have worked out a fairly regular morning routine with my toddler. 


\section{Appendix C}

\section{Instructions for Mothers}

Everything you need to follow the instructions below are provided in this room. Please try to follow the instructions as closely as possible. If you feel you must stop the session, or need any assistance Priscilla will be waiting right outside this room.

\section{Task \#1}

1. Please spend 5 minutes playing with your toddler as you would normally do at home using the toys in the basket.

2. Go on to Task \#2

Task \#2

1. Please explain to your child that it is time to clean-up.

2. Have your child return all of the toys to the basket, helping him/her if needed.

3. Place the toys outside the door when finished.

4. Go on to Task \# 3

Task \#3

1. Please remove the bubbles from the box.

2. Spend 3-5 minutes blowing bubbles with your toddler.

3. You should blow the bubbles and ask your toddler to pop them.

4. Return the bubbles to the box when finished.

5. Go on to Task \#4

Task \#4

1. Please remove the puzzle from the box.

2. Try to interest your child in the puzzle by asking your child to do the puzzle, providing help as needed.

3. When your child has completed the puzzle, put the puzzle away, and go on to Task \# 5.

4. After 3-5 minutes, if your child is unable or unwilling to complete the puzzle, put it away in the box and go on to Task \# 5 . 


\section{Appendix C continued}

Task \#5

1. Please remove the toy bus from the box.

2. Try to interest your child in the bus by asking your child to put the people in it. You may provide help as needed.

3. When your child has placed all of the people in, put the bus back in the box and go on to Task \# 6.

4. After 3-5 minutes, if your child is unable or unwilling to place the toy people in the bus, then put the bus away in the box and go on to Task \# 6 .

Task \# 6

1. Please remove the set of six stacking cups from the box.

2. Try to interest your child in them by asking your to child stack them up, providing help as needed.

3. When your child finishes, put the cups back in the box and go on to Task \# 7.

4. After 3-5 minutes, if your child is unable or unwilling to make a tower, put the cups away in the box and go on to Task \# 7.

Task \#7

1. Please remove the pop-up toy from the box.

2. Try to interest your child in the toy by asking your child to press each button. You may provide help as needed.

4. When your child has pressed all of the buttons, put the pop up toy away in the box and go on to .

5. After 3-5 minutes, if your child is unable or unwilling to push the buttons, put the toy away and go on to Task \# 8.

Task \#8

1. Please put the toy box on the floor and leave the room, closing the door behind you.

2. Remain outside for 2 minutes, and then return to your toddler.

3. You may return sooner if your child seems too distressed. 


\section{Appendix D \\ Rating of Supportive Presence}

7. (Major Criteria: YES;YES)

This mother meets all criteria and subcriteria. If the task is very easy for the child, s/he may not require as much support as indicated by the criteria, so it is appropriate for the mother to allow the child initiative and autonomous work. The difficulty of the task and the level of comprehension and motivation of the individual child may determine how much support the mother should offer and therefore determine how applicable the subcriteria are in this case.

6. (Major Criteria: YES; YES or YES/MINIMAL)

This mother technically meets all criteria (if applicable) but is not quite able to give the child all the support required. It may be the case that the mother is slightly lacking in emotional investment or that she is either a bit over supportive or over controlling. It may be the case that the task is completed so quickly that it is unclear if all the subcriteria would have been met with a longer task. One or two subcritereia might be minimal or even no. Either major criteria scores are yes or one is yes and the other yes/minimal (borderline).

5. (Major Criteria: YES; MINIMAL)

The mother's presence has a positive effect, but she is not supportive and/or involved as in the higher ratings. For this score, one major criteria may be minimally met, but the other is fully met (yes). There may be doubt about two or three subcriteria between minimal and no), or one or two subcriteria may not be met so long as they do not prevent one major criteria from being at least minimally met and the other fully met.

4. (Major Criteria: MINIMAL; MINIMAL or YES; NO)

The mother is not non-supportive but the degree of support is not obvious or striking. She is within the intermediate range of supportiveness. Although the mother adds little to her child's involvement in the task, when the child directly requests aid or support, she gives it. The mother may be more directive than supportive, and try to get the child to follow her instructions rather than supporting the child's efforts. Or she may lack goal directedness due to a lack of motivation or uncertainty in the situation. In this case, the child's motivation might drop. It may be that one major criterion is no, but the other is yes. Another possibility is that both major criteria are scored minimal, and an equal or greater number of subcriteria are scored yes compared to no. 
Appendix D continued

3. (Major Criteria: MINIMAL; MINIMAL or MINIMAL; NO)

The mother is lacking in areas of both major criteria and could be characterized as supportive in only a weak manner. She does have some strengths and may be able to fulfill (yes or minimal) two, three, or even four subcriteria. Both major criteria may be scored minimal; in this case, there are more subcriteria scored no than there are scored yes. Another possibility is that one major criterion is minimal with the other no.

2. (Major Criteria: NO; NO or MINIMAL; NO)

The mother's support is reliably absent but there is no distinct and overt negative quality to the interaction. The mother could not be characterized as overly angry or cold toward the child, but she shows very few or no strengths. Most subcritereia and both major criteria are no, or one is on the border between minimal and no.

1. (Major Criteria: NO; NO)

The mother reacts to the child's angry performance by becoming unmistakably angry, hostile, cold, and/or totally unavailable. Both major criteria are scored no. 
Appendix D continued

Rating of Quality of Assistance

7 (Major Criteria: YES; YES)

This mother is excellent at giving assistance. She is sensitive to he child's schedule. This enables her to provide helpful, well-timed instructions in a clear, orderly fashion. She may be directive if it is in an appropriate, non-intrusive manner. There may be some ambiguity about what is expected or a lack of clarity at one point in the task, but in general the criteria and subcriteria are yes. Both major criteria are yes. One minor subcriteria may be minimal.

6. (Major Criteria: YES; YES or YES; MINIMAL)

This mother 's assistance is very good. The two major criteria are yes, but one may fall between a yes and a minimal. Or all but two subcriteria are yes. This rating may apply to the situation in which the task is solved so quickly that it is not possible to give a lower rating.

5. (Major Criteria: YES; MINIMAL)

This mother is moderately good at giving assistance. It may be that the mother could improve on several dimensions, for example timing, clarity, cooperation. Up to three subcriteria may be no, or four to five may be minimal, as long as one major criterion is scored minimal, with the other yes.

4. (Major Criteria: YES; NO or MINIMAL; MINIMAL)

This mother is between being moderately good and being weak at assisting the child. She does show more than just a few strengths. Both criteria may be minimally met, but the subcriteria are generally yes or minimal, with a greater or equal number scored yes compared to no. Another possibility is that one major criterion is yes but the other is no.

3. (Major Criteria: MINIMAL; MINIMAL or MINIMAL; NO)

The mother's assistance is weak. The mother does show a few strengths in the subcriteria, meeting or minimally meeting three to six. On major criterion may be scored minimal, with more subcriteria scored no than are scored yes. 


\section{Appendix D continued}

2. (Major Criteria:NO; NO or MINIMAL; NO)

This mother's assistance is very poor. Although the mother provides very little assistance overall, she may score a minimal or yes on one or two subcriteria. Both major criteria are scored no, although one may border on minimal.

1. (Major Criteria: NO; NO)

The mother either distracts her child, frustrates him/her, or simply gives no help whatsoever. Both major criteria are scored no. 


\section{Appendix E}

Mother Behavior - Coding Sheet

Subject \#

\section{Supportive Presence}

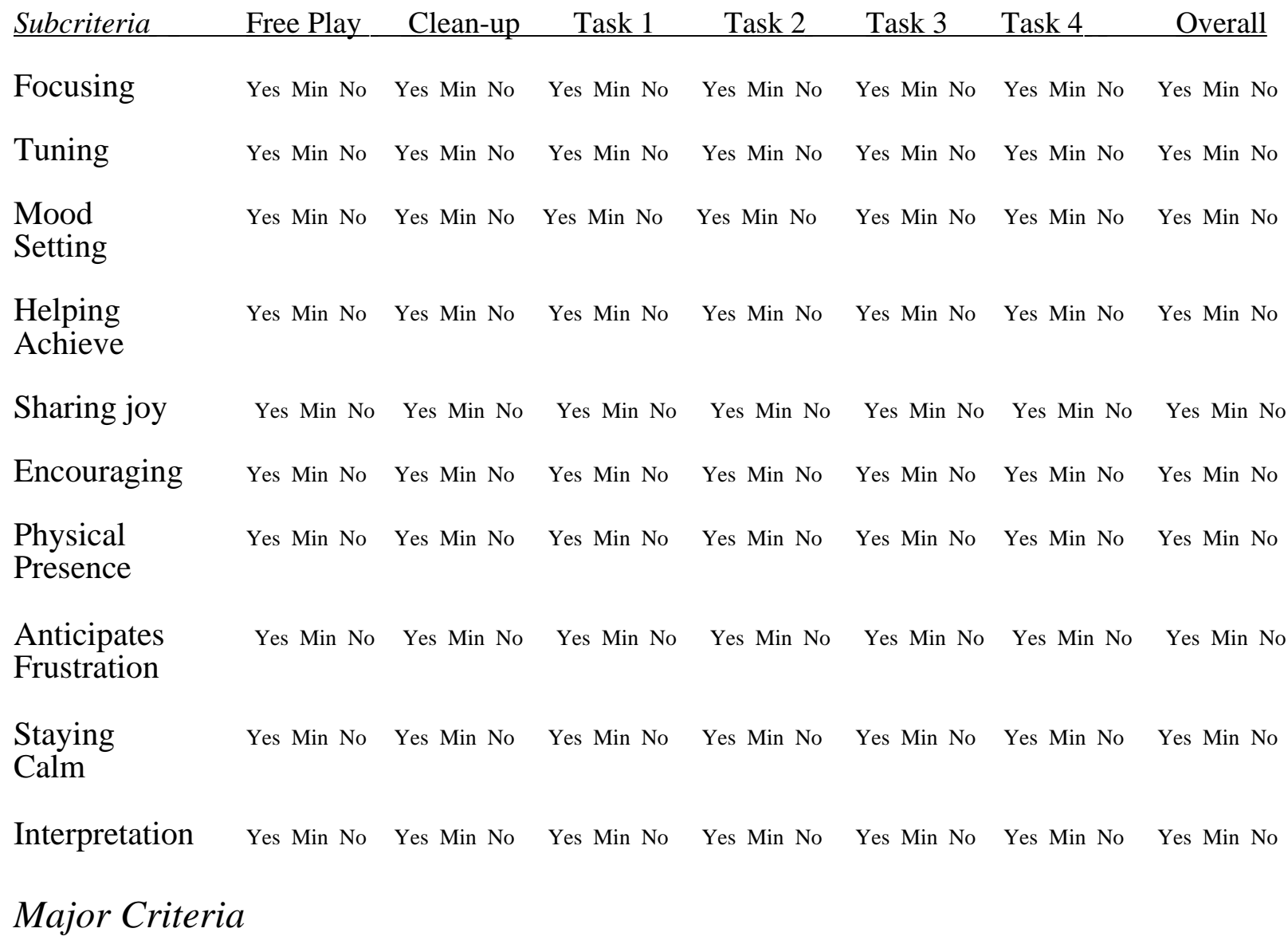

Secure Base $\quad$ Yes Min No Yes Min No Yes Min No Yes Min No Yes Min No Yes Min No Yes Min No

Mother Yes Min No Yes Min No Yes Min No Yes Min No Yes Min No Yes Min No Yes Min No Involvement

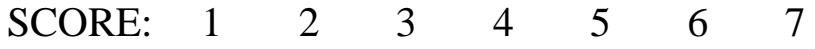




\section{Appendix E continued}

Mother Behavior - Coding Sheet

Subject \#

\section{Quality of Assistance}

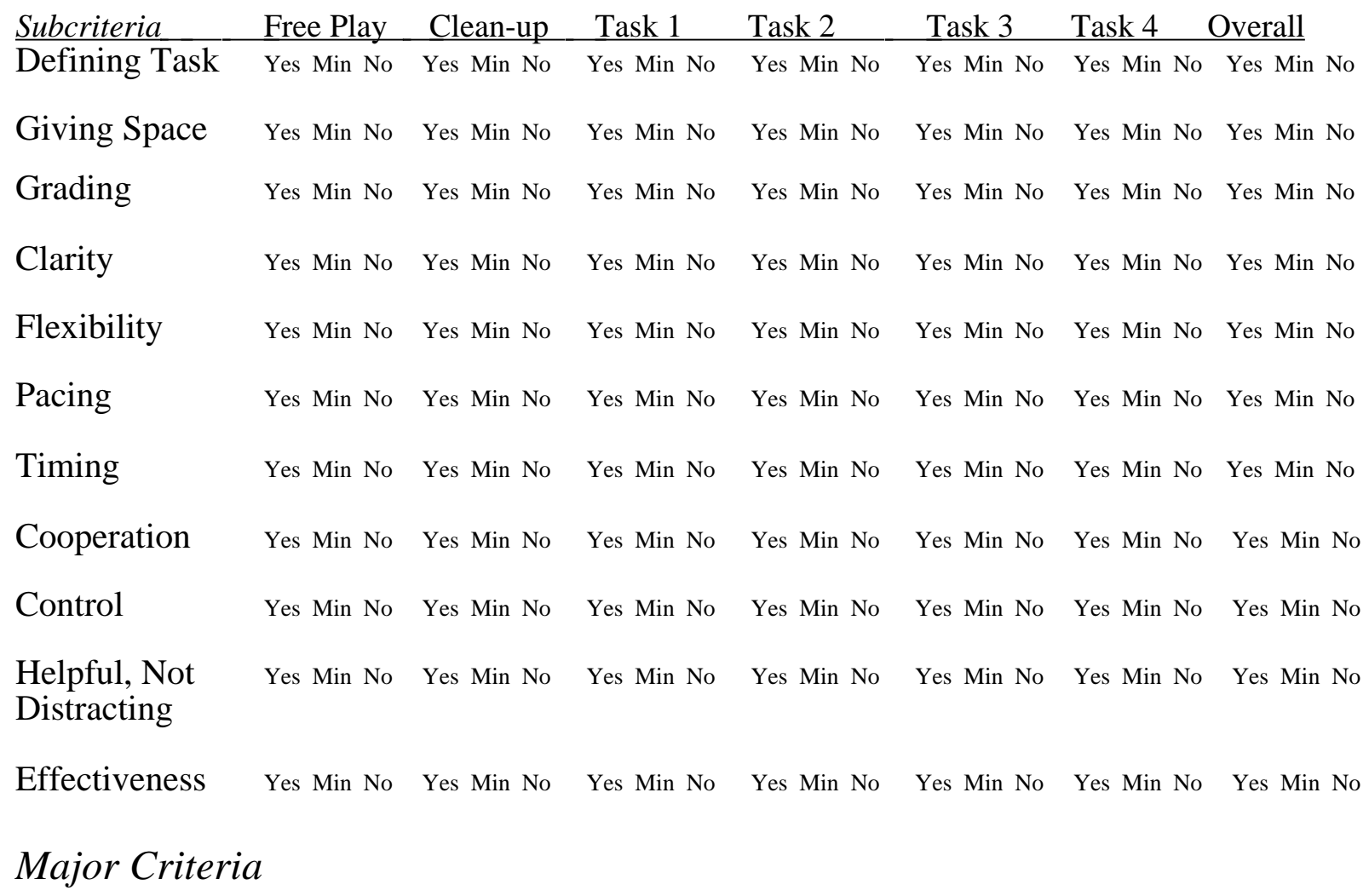

Helping Yes Min No Yes Min No Yes Min No Yes Min No Yes Min No Yes Min No Yes Min No Understand

Minimal Yes Min No Yes Min No Yes Min No Yes Min No Yes Min No Yes Min No Yes Min No Assistance

SCORE: $\quad 1 \quad 2 \quad 3 \quad 3 \quad 4 \quad 5 \quad 6 \quad 6 \quad 7$


Appendix F

\section{Sample Coding of Toddler Behavior}

Child Enthusiasm: Child acts with vigor, confidence, and eagerness to do the tasks. Child takes an active interest in his/her activities, invests effort in them (although not necessarily very persistent), and appreciates successes. Enthusiasm involves both a sense of agency and coordination between affect and behavior. Child should appear well integrated in the sense of directing his/her energy into activities without conflicting motivations or repression of feelings and with confidence that everything is okay. Enthusiasm must be scored for goal-oriented behavior on the tasks (insofar as mother defines these as goals of the situation). Other goals or expressions of excitement may be in service of distracting mother, winning approval, etc., and would not represent enthusiasm here.

1. Child shows no enthusiasm. Child seems hesitant to engage problems or does so "mechanically" and with no evidence of being interested in or excited by his/her performance (although this child may nonetheless be distraught over failures). Child shows an extreme lack of confidence in his/her behavior and is affectively restrained.

2. Child is generally not enthusiastic. Child does take some active interest in his/her activities and becomes engaged for brief periods, but is mostly restrained.

3. Child shows some clear moments of enthusiasm and active engagement in her/his activities but primarily she/he does not engage the situation in this way.

4. Child shows a mixture of enthusiasm and restraint or superficiality of effort. This may occur because the child is very slow in "warming up" to the potential situation or because his/her enthusiasm waxes and wanes and is not reliably invested in the activities.

5. The child is basically interested in the tasks and is enthused for much of the session about these or related activities. There is a sense of harmony between affect and behavior in the child's enthusiasm, but child also has major periods in which this is not the case.

6. Child demonstrates enthusiasm and coordinated affect and behavior for most of the session with only brief and minor periods in which this is not so. The child is quite eager and confident in approaching the tasks and enjoys his/her accomplishments.

7. Child shows high enthusiasm in activities throughout the session. Child approaches goals eagerly, and with some persistence when she/he encounters difficulties, and the intercoordination of affect with behavior gives the child a notable sense of energy in all activities. Child seems to have great confidence that the situation will turn out well and that she/he can trust in her/himself and the support of his/her mother without fear that something "bad" will happen. Child clearly "jumps" on tasks with eagerness and wants to get involved. 


\section{Appendix G}

Toddler Variables - Coding Sheet

Subject \#

Variable Free Play Clean-up Task1_Task2 Task3 Task4 Overall

Enthusiasm
Compliance
Persistence
Avoidance
of Mother
Affection
Towards
Mother
Experience
of the
Session 
Priscilla K.Coleman

\section{CURRICULUM VITAE}

August 1998

\section{Personal History}

Date of Birth:

March 31, 1961

Business Address:

Department of Psychology

The University of the South

P.O. Box 1366

735 University Ave.

Sewanee, TN 37383

Residence:

178 Proctor's Hall

Sewanee, TN 37375

Phone: $\quad$ Office: 931-598-1258

Home: 931-598-2774

Fax:

$931-598-1145$

E-mail

pcoleman@sewanee.edu

Educational History

Southern Connecticut State University, New Haven, CT

Major:

Psychology

Minor:

Studio Art

Degree:

B.A. (GPA: 3.8)

1986

Honors:

Connecticut State Scholar

1983-1986

James Madison University, Harrisonburg, VA

$\begin{array}{ll}\text { Major: } & \text { General Psychology } \\ \text { Degree: } & \text { M.A. (GPA: 4.0) } \\ \text { Master's Thesis: } & \text { Prenatal Expectations of the Maternal Role and } \\ & \text { Postnatal Attitudes Among First-Time Mothers }\end{array}$

West Virginia University, Morgantown, WV

Area of Concentration:

Specialization:

Dissertation topic:

Degree:

Honors:
Life-Span Developmental Psychology

Socio-Emotional Dimensions of Young Family Relations Maternal Self-Efficacy Beliefs as Predictors of Parenting Competence and Toddler Emotional, Cognitive, and Social Development.

Ph.D. (GPA: 4.0)

1998

1995

1997

1997

Recipient of Eberly College of Arts and Sciences

WVU \$200 Student Travel Award

Membership in Phi Kappa Phi, WVU Chapter

1997

Doctoral Qualifying Exams "Pass with Distinction"

1997 Recipient of Eberly College of Arts and Sciences WVU \$450 Doctoral Research Award 


\section{Professional Positions}

Residential Counselor, Homestead Project Inc.,

1988-1989

Ellsworth, ME, half-time position.

Duties: Direct supervision of 13- to 17-year-old residents;

implementation of behavioral treatment plans; maintenance

of resident progress reports.

Research Assistant, Department of Psychology,

1991-1992

James Madison University, Harrisonburg, VA.

Duties: Teaching of undergraduate Experimental Psychology

labs; assisting honor students with research and writing;

preparation and revision of faculty and student manuscripts for

publication; grading of papers and exams.

Instructor of Psychology, Department of Psychology,

1993-1994

James Madison University, Harrisonburg, VA, full-time position.

Duties: Teaching of Psychological Statistics and Experimental Psychology

(both are 4 credit hour lab courses); committee service; statistical consultant for students and faculty.

Instructor of Psychology, Department of Psychology,

James Madison University, Harrisonburg, VA, part-time position.

Duties: Teaching of Psychological Statistics and Experimental

Psychology (two sections per semester).

Teaching Assistant, Department of Psychology,

1995-1997

West Virginia University, Morgantown, WV

Duties: Teaching Introduction to Human Development in

a multi-media classroom; teaching three upper-level

courses (Exceptional Children, Child and Adolescent

Behavior and Development, and Applying to Graduate

School Seminar).

Research Specialist, Center for Assessment and Research Studies,

1997- 1998

James Madison University, Harrisonburg, VA, full-time one-year post.

Duties: Analysis of data, internal and external

report writing, assistance with undergraduate and graduate

honors theses, and supervision of four undergraduate students' directed

research projects. Representative projects included the following:

1) development of a source book pertaining to

writing assessment methods in higher education for

the National Post-Secondary Education Cooperative;

2) conducting a study of the association between college students'

intercultural experiences and cross-cultural adaptability;

3) writing of a FIPSE grant for supplementary

funding of a new doctoral program in assessment at JMU.

The FIPSE grant was accepted and funded in the amount of $\$ 145,000.00$ over a 3-year period.

Assistant Professor of Psychology, Department of Psychology,

1998 - Present

University of the South, Sewanee, TN, tenure-track position.

Duties: Teaching Development and Personality lab, Social Psychology,

Research Methods, Child Development with a lab, and Educational Psychology.

Expected to maintain an active research program with student involvement and provide departmental, university, and community service. 


\section{Publications}

Carlton, C. L., Nelson, E. S., \& Coleman, P. K. (in press). College students' attitudes toward abortion and commitment to the issue. Social Science Journal.

Coleman, P. K., \& Karraker, K. H. (1998). Self-efficacy and parenting quality: Findings and future applications. Developmental Review, 18, 47-85.

Coleman, P. K., \& Nelson, E. S.(in press). Attitudes toward abortion and interest in the issue as determinants of perceptions of the appropriate level of male involvement in abortion decisions. Journal of American College Health.

Coleman, P. K., \& Nelson, E. S. (in press). The quality of abortion decisions and college students' reports of post-abortion emotional sequelae and abortion attitudes. Journal of Social and Clinical Psychology. Expected publication date is December, 1998.

Coleman, P. K., \& Nelson, E. S., \& Sundre, D. (in press). The relationship between prenatal expectations and postnatal attitudes among first-time mothers. International Journal of Reproductive and Infant Psychology.

Erwin, T.D., \& Coleman, P. K. (in press). The Influence of intercultural experiences and second language proficiency on college students' cross-cultural adaptability. International Education.

Nelson, E. S., Coleman, P. K., \& Swager, M. (1997). Attitudes toward the level of male involvement in abortion decisions. Journal of Humanistic Education and Development, 25, 217-224.

Nelson, E. S., Karr, K., \& Coleman, P. K. (1995). The relationships among daily hassles, optimism, and reported physical symptoms. Journal of College Student Psychotherapy, 10, 11-26.

\section{Manuscripts Submitted for Publication}

Coleman, P. K., Franz, W., \& Reardon, D. The salience of pressure to obtain an abortion as a predictor of post-abortion adjustment in adolescents and adult women. Submitted to the Journal of Adolescent Health.

Coleman, P. K., \& Karraker, H. K. Parenting self-efficacy among mothers of school-age children: Conceptualization, measurement, and predictors. Submitted to Family Relations.

Coleman, P. K., \& O’Reilly, A. W. Infant attachment as a dynamic system. Submitted to Human Development.

Erwin, T.D., Coleman, P. K., \& Orlando, M. Novelty and persistence among college students: A pilot study of the Curiosity Index. Submitted to Psychological Reports.

\section{Presentations at Professional Meetings}

Coleman, P. K. (April, 1997). Toward a dynamic system of child development: The importance of changing environments and person-context relations. In A.W. O'Reilly (Chair), Dynamic systems theory: Taking seriously the complexity of organism-behavior-environment relations. Paper symposium conducted at the meeting of the Society for Research in Child Development, Washington, DC.

Coleman, P. K., \& Nelson, E. S. (April, 1997). The quality of abortion decisions and college students' reports of post-abortion emotional sequelae and abortion attitudes. Poster presented at the meeting of the Society for Research in Child Development, Washington, DC.

Karraker, H. K., \& Coleman, P. K. (May, 1998). Parenting self-efficacy beliefs among mothers of school age children. Poster presented at the American Psychological Society, 10th Annual Convention, Washington, DC. 


\section{Conference Submissions:}

Coleman, P. K., \& Karraker, H. K. (April, 1999). Maternal Self-Efficacy Beliefs as Predictors of Parenting Competence and Toddlers' Behavior and Development. Poster submitted for presentation at the meeting of the Society for Research in Child Development, Albuquerque, NM.

Karraker, H. K., \& Coleman, P. K. (April, 1999). Mothers' predictions of their toddlers' performances on the Bayley Scales of Infant Development. Poster submitted for presentation at the meeting of the Society for Research in Child Development, Albuquerque, NM.

\section{Professional Affiliations}

Society for Research in Child Development

American Psychological Association

1996-present

American Psychological Society

1996-present

1998-present

\section{Professional Activities}

Member of the Advising Committee, Department of Psychology,

1993-1994

James Madison University, Harrisonburg, VA.

Member of the General Psychology Program Committee,

Department of Psychology, James Madison University, Harrisonburg, VA

1993-1994

Member of the Diversity Committee, Department of Psychology,

1995-1997

West Virginia University, Morgantown, WV.

Member of the Alumni Fund Committee, Department of Psychology,

1995-1996

West Virginia University, Morgantown, WV

Elected Student Representative to the Developmental Training Committee,

Department of Psychology, West Virginia University, Morgantown, WV.

Member of Casey Martin's General Psychology Master's

1995-1996

Thesis Committee at James Madison University, Harrisonburg, VA.

Member of Ada Boston's Honors Thesis Committee

1995-1996

at West Virginia University, Morgantown, WV

Member of Tina Alessandria's General Psychology Master's

1997-1998

Thesis Committee at James Madison University, Harrisonburg, VA

1997-1998

Member of Tina Marie Blair's Undergraduate Honor's

Thesis Committee at James Madison University, Harrisonburg, VA

Member of Amy Greenough's Undergraduate Honor's

1997-1998

Thesis Committee at James Madison University, Harrisonburg, VA

Member of Kristen Finlayson's Undergraduate Honor's

Thesis Committee at James Madison University, Harrisonburg, VA

1997-1998 


\section{Workshops Conducted}

Assisted Dr. Katherine Karraker with a one-day concentrated training workshop on the

June 1996

Bayley Scales of Infant Development conducted for professionals with a variety

of disciplinary affiliations. Topic covered included issues in the assessment of infant intelligence,

general description of the Bayley Scales, considerations in testing infants, guidelines on

learning to administer the Bayley Scales, demonstration of items, and an overview of the

structure and scoring of the test.

Invited to provide an afternoon seminar for psychology graduate students at James

April 1998

Madison University pertaining to the personal and academic challenges incurred

across the transition from masters level programs to doctoral training. Format was

a combination of lecture and informal discussion sessions.

\section{Work in Progress}

Coleman, P. K., \& Karraker, K. H. The development of maternal self-efficacy and its relationship to behavioral competency (data collection in progress).

This is a multivariate, longitudinal study with five points of measurement, beginning at 12 weeks of pregnancy and continuing to 6 months postpartum, involving a combination of survey research methodology and laboratory observation.

Assisting Dr. Katherine Karraker with the research and writing for an edited book chapter. The title of the book is Infant Development: Ecological Perspectives and the chapter is entitled "Gender and Temperament Influences on Caregiving Context" The editors include Dr. Hiram E. Fitzgerald (Michigan State University), Dr. Katherine Karraker (West Virginia University), and Dr. Tom Luster (Michigan State University). The chapter will be completed by May 15, 1999 and the final copy of the book is expected to be submitted to Garland Press for production and publication by November 15, 1999

Assisting Dr. T. Dary Erwin with an extensive revision of his Scale of Intellectual Development, designed to assess college students' level of intellectual development based on William Perry's model of intellectual and ethical development. The instrument was recently administered to 800 college sophomores along with a number of other developmental measures. We have also created a new scenario version of the measure that has been piloted with 180 college sophomores. 


\section{Professional References}

Dr. Stanley Cohen

Department of Psychology

West Virginia University

114 Oglebay Hall

Morgantown, WV 26506-6040

(304) $293-2001$ x 641

Dr. T. Dary Erwin

Center for Assessment and Research Studies

James Madison University

Harrisonburg, VA 22807

(540) 568-6706

Dr. Katherine Karraker

Department of Psychology

West Virginia University

114 Oglebay Hall

Morgantown, WV 26506-6040

(304) 293-2001 x 625

Dr. Cheryl McNeil

Department of Psychology

West Virginia University

114 Oglebay Hall

Morgantown, WV 26506-6040

(304) 293-2001 x 677

Dr. Eileen Nelson

Department of Psychology

James Madison University

Harrisonburg, VA 22807

(540) 568-6002

Dr. Anne O'Reilly

Department of Psychology

West Virginia University

114 Oglebay Hall

Morgantown, WV 26506-6040

(304) 293-2001 x 644

Dr. Hayne Reese

Department of Psychology

West Virginia University

114 Oglebay Hall

Morgantown, WV 26506-6040

(304) 293-2001 x 643 